\title{
Computational models of memory consolidation and long-term synaptic plasticity during sleep
}

\author{
César Rennó-Costa ${ }^{\mathrm{a}, \mathrm{b}, 1}$, Ana Cláudia Costa da Silva ${ }^{\mathrm{a}, \mathrm{b}, \mathrm{c}, \mathrm{d}, 1}$, Wilfredo Blanco ${ }^{\mathrm{a}, \mathrm{c}, \mathrm{e}}$, Sidarta Ribeiro ${ }^{\mathrm{c}, *}$

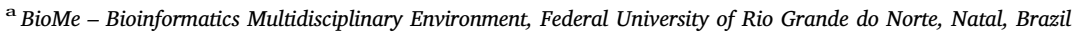 \\ ${ }^{\mathrm{b}}$ Digital Metropolis Institute, Federal University of Rio Grande do Norte, Natal, Brazil \\ ${ }^{\mathrm{c}}$ Brain Institute, Federal University of Rio Grande do Norte, Natal, Brazil \\ ${ }^{\mathrm{d}}$ Federal University of Paraiba, João Pessoa, Brazil \\ e State University of Rio Grande do Norte, Natal, Brazil
}

A R T I C L E I N F O

\section{Keywords:}

Homeostasis

Sequential

Replay

Active consolidation

Embossing

Down-scaling

Up-scaling

Simulation

LTP

LTD

\begin{abstract}
A B S T R A C T
The brain stores memories by persistently changing the connectivity between neurons. Sleep is known to be critical for these changes to endure. Research on the neurobiology of sleep and the mechanisms of long-term synaptic plasticity has provided data in support of various theories of how brain activity during sleep affects long-term synaptic plasticity. The experimental findings - and therefore the theories - are apparently quite contradictory, with some evidence pointing to a role of sleep in the forgetting of irrelevant memories, whereas other results indicate that sleep supports the reinforcement of the most valuable recollections. A unified theoretical framework is in need. Computational modeling and simulation provide grounds for the quantitative testing and comparison of theoretical predictions and observed data, and might serve as a strategy to organize the rather complicated and diverse pool of data and methodologies used in sleep research. This review article outlines the emerging progress in the computational modeling and simulation of the main theories on the role of sleep in memory consolidation.
\end{abstract}

\section{Introduction}

The brain preserves recently acquired memories through a consolidation process that structurally changes the synapses (Bliss \& Collingridge, 1993; Davis \& Squire, 1984; Jarome \& Helmstetter, 2014). Several decades of research have uncovered behavioral, electrophysiological and molecular evidence that sleep is critical for memory consolidation (Diekelmann \& Born, 2010; Marshall, Helgadóttir, Mölle, \& Born, 2006; Rasch \& Born, 2013; Rudoy, Voss, \& Westerberg, 2009; Stickgold \& Walker, 2013; Vorster \& Born, 2015; Walker \& Stickgold, 2004). During sleep, the brain produces generalized alterations in neuronal dynamics (Blanco et al., 2015; Gervasoni et al., 2004; Hobson \& McCarley, 1971; Ma, Shi, Peng, \& Yang, 2018; Noda, Manohar, \& Adey, 1969). Given the activity-dependent nature of synaptic plasticity (Bliss \& Collingridge, 1993; González-Rueda, Pedrosa, Feord, Clopath, \& Paulsen, 2018), these changes trigger molecular cascades that ultimately produce long-lasting synaptic modifications. While several different theories have been proposed to explain the effect of sleep on memories, a consensus is still lacking about the ruling principles that link sleep-dependent changes in brain activity to memory consolidation.

A first topic of contention originates from the observation that synapses can either be strengthened (long-term potentiation, LTP) or be weakened (long-term depression, LTD) depending on how they are stimulated (Bliss \& Lømo, 1973; Hager \& Dringenberg, 2010; Hölscher, Anwyl, \& Rowan, 1997; Hyman, Wyble, Goyal, Rossi, \& Hasselmo, 2003; Pavlides, Greenstein, Grudman, \& Winson, 1988) (For more details, see Box A). The synaptic homeostasis hypothesis (SHY) posits that the slow rhythm of brain waves during sleep, -specially hippocampal sharp wave ripples, weakens synaptic connections, which in turn promotes the forgetting of unimportant memories (Tononi \& Cirelli, 2003, 2014). On the other hand, the reactivation (or replay) theory proposes that the repetition during sleep of brain activity first experienced during waking would reinforce some, but not all, synaptic patterns (Chauvette, Seigneur, \& Timofeev, 2012; Foster \& Wilson, 2006; Pavlides \& Winson, 1989). Both SHY and the replay theory relate mainly to slow-wave sleep (SWS), which spans most of the sleep in vertebrates. SHY accounts well for forgetting and even a relative strengthening of synapses (i.e.,

\footnotetext{
* Corresponding author at: Av. Nascimento de Castro 2155, Natal, RN 59056-450, Brazil.

E-mail address: sidartaribeiro@neuro.ufrn.br (S. Ribeiro).

${ }^{1}$ These authors contributed equally to the work.
} 
Box A

Long-term synaptic plasticity

The synaptic memory doctrine postulates that molecular modifications in the synapse strength allow the brain to store, maintain and retrieve memories (Lisman, 2017a) (Takeuchi, Duszkiewicz, \& Morris, 2014). Such a hypothesis is alternative to the idea that memories are stored as changes in the cellular properties of neurons (Mozzachiodi \& Byrne, 2010). Synapse strength is proportional to synapse size and exhibits an approximate 10-fold gradation (Liu, Hagan, \& Lisman, 2017), granting ample space for storing information. For this reason, the brain implements many different mechanisms of synaptic plasticity (Citri \& Malenka, 2008). A standard protocol to observe changes in synaptic strength consists in comparing the amplitude of evoked post-synaptic potential (EPSP) produced with electrical stimulations of the same magnitude on two different occasions (Nicoll \& Malenka, 1999). Changes can be short-lived as in the processes of neural facilitation (Del Castillo \& Katz, 1954), synaptic augmentation (Magleby \& Zengel, 1976), synaptic depression (Tsodyks \& Markram, 1997), posttetanic potentiation (Bao, Kandel, \& Hawkins, 1997) or synaptic fatigue (Armbruster \& Ryan, 2011). However, within the synaptic memory doctrine, one would be focused on the long-lasting changes of synaptic strength, termed Long-term potentiation (LTP) and Long-term depression (LTD) for positive and negative changes, respectively (Bliss \& Collingridge, 1993; Morris, 2003). The causal link between memories and LTP/LTD has been established by experiments that observed the cellular signatures of LTP after learning (Whitlock, Heynen, \& Shuler, 2006) and that could evoke or inhibit a memory trace by producing LTP and LTD (Nabavi et al., 2014). Therefore, it is reasonable to consider that long-term synaptic changes have a direct impact on memory.

The mechanisms underlying LTP and LTD are still under investigation, but many of the molecular players are known. For instance, the kinases CaMKII (Lisman, 1985; Sanhueza \& Lisman, 2013) and Protein Kinase M-zeta (PKM-zeta) (LeBlancq, McKinney, \& Dickson, 2016; Sacktor, 2012; Tsokas et al., 2016) have been hypothesized to regulate memory storage. The processes involve changes in sub-synaptic structures such as the volume of the presynaptic button, active zone, postsynaptic density (PSD) and dendritic spine (Arellano, BenavidesPiccione, Defelipe, \& Yuste, 2007; Bosch et al., 2014; Meyer, Bonhoeffer, \& Scheuss, 2014). Such processes depend on protein synthesis (Frey, Krug, Reymann, \& Matthies, 1988; Kelly, Mullany, \& Lynch, 2000). As a result, the expression of specific immediate early genes (IEG) involved with direct or indirect synaptic remodeling, such as Arc and Zif-268, respectively, work as signatures of long-term plasticity (Abraham, Dragunow, \& Tate, 1991). Importantly, the genetic cascade promoted by these genes is activity-dependent (Penke \& Chagneau, 2011), pointing to potential triggers of synaptic plasticity.

Paired stimulation of pre- and post-synaptic neurons can produce LTP (Bliss \& Lømo, 1973) and LTD (Hager \& Dringenberg, 2010). Notably, LTP or LTD can be induced in single synapses (Matsuzaki, Honkura, Ellis-Davies, \& Kasai, 2004). Aligned with the abundant experimental evidence that coincident presynaptic and postsynaptic activity promote long-term plasticity (Lisman, 2017b), the Hebbian plasticity rule remains the standard model of synaptic plasticity (Hebb, 1949). The Hebbian rule designates that connected neurons with coincident firing enhance their connectivity. In contrast, synapses between neurons with non-paired firing are weakened. The STDP rule incorporates to the Hebbian model the temporal gap between pre- and post-synaptic action potentials, as observed experimentally (Levy \& Steward, 1983; Markram, Lübke, Frotscher, \& Sakmann, 1997; Sjöström, Turrigiano, \& Nelson, 2001). The alternative class of plasticity rules, known as non-Hebbian, imply that synaptic strengths can be self-regulated to maintain or optimize system functionality, avoiding saturation (Turrigiano, 2017), as also observed empirically (Turrigiano et al., 1998).

synapses can become weaker but relatively stronger than other synapses that are also depressed), but collides with the mounting experimental evidence of sleep-dependent memory restructuring, creativity and mnemonic enhancement, which pose less of a challenge to replay theory (Donlea, Thimgan, Suzuki, \& Gottschalk, 2011; Fischer, Drosopoulos, Tsen, \& Born, 2006; Lerner, 2017a; Wagner, Gais, Haider, Verleger, \& Born, 2004; Yordanova, Kolev, Wagner, Born, \& Verleger, 2012). It is worth mentioning that the evidence of replay also during quiet wakefulness (wake replay), in association with the occurrence of hippocampal sharp wave ripples (Jadhav, Kemere, \& German, 2012), poses a question mark on the replay theory. This contradiction may be circumvented by extending to quiet wakefulness the same cognitive properties ascribed to SWS, based on the occurrence of sharp wave ripples in both states. The sharp wave ripple represents an instance of extreme synchronization for hippocampal neurons (Buzsáki, 1986; Chrobak \& Buzsáki, 1994; Csicsvari, Hirase, Czurkó, \& Mamiya, 1999), which fire sequentially as temporally compressed versions of firing patterns originally observed during active waking (Lee \& Wilson, 2002; Nádasdy, Hirase, Czurkó, Csicsvari, \& Buzsáki, 1999; Skaggs \& McNaughton, 1996; Wilson \& McNaughton, 1994).

A second controversial issue relates to the specific roles played by two of the main states of sleep, SWS and rapid-eye-movement sleep (REM). These states cyclically recur during sleep, with a broad diversity of episode durations, and quite variable levels of neural activity (Blanco et al., 2015; Gervasoni et al., 2004; Hobson \& McCarley, 1971; Noda et al., 1969). A major dispute is whether each sleep state has a different function for the consolidation of memory and, if so, what would be the function of each state. The sequential theory postulates that SWS weakens irrelevant synaptic patterns, while REM sleep strengthens the relevant ones (Giuditta et al., 1995; Giuditta, 2014). The synaptic embossing theory proposes that trace reverberation during SWS is followed during REM sleep by an activity-dependent combination of synaptic strengthening and weakening in complementary circuits, respectively tagged or untagged by relevant waking experience (Ribeiro, 2012). The theory of active systems consolidation during sleep assumes this phenomenon to occur exclusively during SWS, i.e. not during REM sleep (Born \& Wilhelm, 2012).

Despite the wealth of behavioral, electrophysiological and biochemical evidence in support of each of the theories of sleep and memory (Born \& Wilhelm, 2012; Born, Rasch, \& Gais, 2006; Diekelmann \& Born, 2010; Marshall \& Born, 2007; Puentes-Mestril \& Aton, 2017; Rasch \& Born, 2013; Tononi \& Cirelli, 2014; Vorster \& Born, 2015) (For more details, see Box B), the complexity of the mechanisms involved and the diversity of methodologies make it hard to compare and test the grounds of each theory. Notwithstanding theoretical mismatches, the underlying processes described by the several competing theories are not necessarily contradictory. Through the analysis of the available empirical evidence, it should be possible to draw a more precise picture of the role of sleep in learning and memory. Here we focus on the computational evidence obtained from modeling and simulation studies (For more details, see Box C). Our goal here is to assess how the interaction between theory and experimentation using computer models has been developing in the sleep and memory field.

In the following sections, we present a brief review of each of the major classes of theories regarding sleep's role in memory consolidation, followed by a survey on the different simulation studies that 
Box B

Molecular mechanisms of sleep-dependent plasticity

The investigation of sleep-dependent plasticity during development uncovered several mechanisms of synaptic plasticity during sleep, and thus generated evidence in support of theories that predict phenomena outside the boundaries set by SHY (Frank, 2012). Studies of juvenile rats found that REM sleep deprivation modulates plasticity in the visual cortex (Shaffery, Lopez, Bissette, \& Roffwarg, 2006), in a process mediated by the brain-derived neurotrophic factor (BDNF) (Shaffery, Lopez, \& Roffwarg, 2012). In the hippocampus of juvenile rats, REM sleep deprivation makes LTP unstable and decreases the protein levels of glutamatergic synaptic components such as N-methyl-d-aspartate (NMDA) receptor subunit 2B and the AMPA receptor subunit 1 (Lopez et al., 2008). Ocular dominance plasticity in the primary visual (V1) cortex caused by monocular deprivation in juvenile cats (Hubel \& Wiesel, 1969) was found to be enhanced by sleep (Frank, Issa, \& Stryker, 2001; Seibt et al., 2012), in a process that involves activation of the NMDA receptor and the cAMP-dependent protein kinase (PKA), as well as the downstream phosphorylation of CaMKII and extracellular signal-regulated kinase (ERK) (Aton et al., 2009). Importantly, REM sleep has been shown to be necessary for ERK phosphorylation involved in ocular dominance plasticity in the V1 cortex (Dumoulin Bridi et al., 2015). The different theories of sleep and memory differ widely in regard to the dependence on the role of the different states of sleep and the associated patterns of synaptic modification. This section will review these main theories, with reference to their empirical scaffold. It is important to consider that the different theories often reflect diverse bodies of empirical evidence and, therefore, likely describe synaptic modifying mechanisms that are complementary rather than contradictory.

The debate on whether sleeps harbors Hebbian mechanisms of plasticity in adult and developing animals unraveled with recent studies using in vivo transcranial two-photon imaging to quantify dendritic spines in mice exposed to motor learning, deprived of specific sleep states and subjected to pharmacological treatments (Li, Ma, Yang, \& Gan, 2017; Yang et al., 2014). Wenbiao Gan and his team showed that NREM sleep that follows motor learning promotes the formation of branch-specific dendritic spines by way of trace reverberation and activation of NMDA receptors (Yang et al., 2014), a process that leads to persistent synaptic plasticity (Cichon \& Gan, 2015). REM sleep promotes the pruning of new dendritic spines but also the persistence of selected ones, again by way of NMDA receptor activation (Li et al., 2017). Altogether, the results constitute direct evidence of Hebbian synaptic strengthening in combination with non-Hebbian synaptic weakening during sleep. If calcium signaling during regular sleep facilitates the selective strengthening of specific synapses, sleep deprivation decreases calcium signaling and long-term plasticity in the rodent hippocampus (Havekes et al., 2014; Havekes, Park, Tolentino, et al., 2016; Ravassard et al., 2009, 2016; Vecsey et al., 2009), leading to elevated levels of the protein cofilin, which disassembles actin filaments and leads to spine loss (Havekes, Park, Tudor, et al., 2016).

Evidence seemingly at odds with most studies reviewed above came from a neurophysiological investigation by Gina Turrigiano and collaborators of neuronal firing rates in the visual cortex of juvenile rats subjected to monocular deprivation (Hengen, Torrado Pacheco, McGregor, Van Hooser, \& Turrigiano, 2016). As expected, firing rates dropped dramatically due to the contralateral deprivation. However, while rates remained low during ensuing sleep, they increased back to their original levels during subsequent waking periods. This led to the proposal that "sleep inhibits, rather than promotes, firing rate" (Hengen et al., 2016). In possible agreement with this notion, recordings in the CA1 field of the hippocampus of adult rats showed that firing rates decrease and firing synchrony increases across sleep periods (Miyawaki \& Diba, 2016; Vyazovskiy et al., 2009).

One study of CA1 neurons showed that rates increase during NREM sleep but decrease even more during REM sleep, in correlation with the power of theta oscillations (Grosmark et al., 2012). This in-depth investigation of multiple NREM/REM cycles presents an apparent challenge to SHY: Since NREM sleep greatly enhances the number of synapses (Yang et al., 2014), the consequence may be a net increase in synaptic strength and therefore an overall increase in firing rates, which would directly contradict SHY. The solution of this conundrum requires differentiating net effects from localized, synapse-specific effects. Indeed, REM sleep triggers selective synaptic enhancement combined with overall synaptic decimation (Li et al., 2017), a mixture expected to cause net rate decrease, but with selected firing rate increase in specific neurons.

provide computational evidence in favor of specific classes of theories. We classify the theories according to whether they include (i) any process for the homeostatic regulation of synaptic weights, (ii) selective potentiation of specific synapses through activity replay, or (iii) assignment of different roles for each of the sleep states. We describe the methodology of each simulation study and discuss the level of evidence that the results provide in support to the reference theory. Further, we discuss and propose how the use of computational approaches could potentially integrate the many different theories of sleep and memory into a single theoretical framework.

\section{Computational studies of the homeostatic regulation of synaptic weights}

Immediate early genes (IEG) (Cole, Saffen, Baraban, \& Worley, 1989; Kaczmarek \& Chaudhuri, 1997) mediate morphological changes in neuronal dendrites and axons, which are required for LTP, LTD and the stabilization of lasting memories (Alberini, 2009; Bozon et al., 2003; Chowdhury et al., 2006; Messaoudi et al., 2007; Shepherd et al., 2006; Waung, Pfeiffer, Nosyreva, Ronesi, \& Huber, 2008). For this reason, in the mid-1990s experiments began to examine whether the positive effects of sleep on memory could be caused by the activation of IEG during sleep. The first experiments failed to corroborate the hypothesis: IEG transcription was actually downregulated by sleep (Pompeiano, Cirelli, \& Tononi, 1992, 1994, 1995, 1997). This led the researchers to propose that synaptic strengthening occurs exclusively during waking, with sleep being responsible for their weakening, which would prevent saturation and allow more learning to occur in the next waking period (Tononi \& Cirelli, 2003). This theory was called the synaptic homeostasis hypothesis (SHY), since the excess of synaptic strengthening during wakefulness would be balanced by generalized non-Hebbian synaptic weakening during sleep. SHY is mechanistically based on the notion that the slow rhythm of brain waves during SWS weakens synaptic connections, erasing the weaker ones (de Vivo et al., 2017; Tononi \& Cirelli, 2003, 2014; Vyazovskiy, Cirelli, Tononi, \& Tobler, 2008). SHY is reminiscent of the phenomenon of homeostatic plasticity, i.e. natural compensatory changes in synaptic strength able to prevent extreme potentiation or depotentiation due to activity perturbations (Turrigiano \& Nelson, 2004; Turrigiano, Leslie, Desai, Rutherford, \& Nelson, 1998). An even earlier inspiration for SHY was the "reverse learning" theory of sleep, by which undesired spurious memory traces would be erased during sleep, not strengthened (Crick \& 
Box C

Evidence from computational modeling and simulations

Computational modeling and simulations reproduce in silico the behavior of a dynamic system using a mathematical model. Scientific evidence drawn from computational studies fall into three categories of supportive evidence: reproductive, predictive, and functional. When the simulated dynamics are derived from mathematical models with sufficient detail about the actual biological system, the reproduction of experimental data constitutes evidence that the observed phenomenon develops from the modeled anatomical structures. The predictive evidence is at stake when information about the structure of the biological system is available, but not all aspects of its dynamics are known. Simulations can inform specific behavioral signatures of a given theory, which in turn can be validated or falsified by further experimental studies. The last class of evidence consists of a demonstration that some aspects of a given theory provide a functional advantage to the modeled system. In the specific case of a learning and memory system, it is possible to evaluate how the network pattern related to the initial encoding is affected, both qualitatively and quantitatively, by a simulation of sleep.

The use of computational models as a strategy to bridge theory and experimentation has become a routine scientific practice in neuroscience (e.g., Valton, Romaniuk, Douglas Steele, Lawrie, \& Seriès, 2017) and is increasingly welcomed by research editors (Shou, Bergstrom, Chakraborty, \& Skinner, 2015). The computational approach allows scientists to describe the theoretical formulations formally and, using simulations, directly confront theoretical predictions in the form of simulated data with experimental data obtained from studies with animal models as well as humans. This close link between theory and experimentation supports the design of new theory-oriented experiments and the development of experimentally-constrained models. Some specific research areas in neuroscience experienced a fastpaced advance following this strategy (Churchland \& Sejnowski, 2016). For example, our understanding of the dynamics of local neuronal electrochemistry rose with the cross-talk between biophysically-detailed models (Hodgkin \& Huxley, 1952) and patch clamp techniques (Neher \& Sakmann, 1976). In systems neuroscience, theories about the brain mechanisms underlying spatial cognition (Tolman, 1948) drove the experimental observation of neuronal correlates of position, such as place cells (O'Keefe \& Nadel, 1978) and grid cells (Hafting, Fyhn, Molden, Moser, \& Moser, 2005), which in turn started a virtuous loop with modelers that led to the development of interconnected theoretical and experimental studies (Lu et al., 2013; McNaughton, Battaglia, Jensen, Moser, \& Moser, 2006; Rennó-Costa et al., 2010; Yoon et al., 2013).

Mitchison, 1983). Altogether, these theories have in common the idea that sleep promotes forgetting.

A first class of computational studies (Table 1a) that are particularly relevant to SHY provides mechanistic descriptions and simulations of the cellular and network mechanisms underlying slow-wave activity observed during sleep and the transition to an awake brain state (Bazhenov, Timofeev, Steriade, \& Sejnowski, 2002; Compte, SanchezVives, McCormick, \& Wang, 2003; Esser, Hill, \& Tononi, 2007, 2009; Hill \& Tononi, 2005; Komarov et al., 2018). Although these studies do not deal directly with plasticity issues, they provide compelling computational evidence that changes in specific anatomical variables, possibly mediated by plasticity or neuromodulatory influence, have a substantial impact on brain dynamics. These observations are valuable to SHY as this theory postulates that the role of sleep is to counteract the anatomical modifications introduced during waking, so as to keep brain dynamics within a functional range. For these studies, the authors built large-scale computational models of the thalamocortical system aiming to reproduce the patterns of neuronal activity during waking and sleep. Such models include networks of excitatory and inhibitory neurons with detailed biophysics, including variables such as potassium leak conductance and synaptic efficacy, and external stimuli emulating a sensory input pathway. The strategy consisted of manipulating the anatomical variables to assess effects on specific features of network activity that can be related to sleep or waking brain states. More specifically, the authors evaluated the level of neuronal synchronization, the presence of slow-frequency oscillations and the impact of external stimuli on network dynamics. The waking state manifested a low level of synchronization, an absence of slow oscillations and a substantial impact of external perturbations in network dynamics. In contrast, the sleep state exhibits a high level of neuronal synchronization, a presence of slow oscillations, and weak variance when subjected to external stimuli. Among these models, it is worth mentioning a recent study that replicated many of the previous studies results in a simulation of a network with 1.36 million neurons (Komarov et al., 2018). This largescale simulation revealed brain dynamics patterns such as traveling waves, which were observed in SWS sleep (Sheroziya \& Timofeev, 2014), but that could not be replicated in the above mentioned smallscale simulations. Traveling waves propagate across the cortical surface and have been implicated with information transfer across brain regions (Rubino, Robbins, \& Hatsopoulos, 2006; Zhang, Watrous, Patel, \& Jacobs, 2018).

These different models, although showing considerable methodological differences in their implementation, can overall capture the initiation, maintenance, and termination of the slow oscillation. Of particular interest to SHY, one singular model provided a link between synaptic strength and the level of slow-wave activity found in simulated brain dynamics (Esser et al., 2007). The simulations revealed that a reduction in cortical synaptic strength leads to a decrease of slow-wave activity during sleep, with a decreased incidence of large-amplitude slow waves, a decrease in their slope, and an increase in the number of multipeak waves. Although the model was constructed based on electrophysiological recordings from cats, the predictions of the model could also explain gradual changes in brain activity between early- and late-sleep observed with local field potential (LFP) recordings in rats (Vyazovskiy et al., 2007) and high-density electroencephalographic (EEG) recordings in humans (Riedner et al., 2007).

The second class of computational studies related to SHY (Table 1b) considers the role of plasticity in concert with the changing brain dynamics across the sleep-wake cycle. One approach included a spiketiming-dependent plasticity (STDP) rule (Levy \& Steward, 1983) to the thalamocortical model cited in the paragraph above (Olcese, Esser, \& Tononi, 2010). The plasticity rule, aligned with predictions made by SHY, produced an increase in the overall synaptic strength when the network activity was in the awake mode. In their simulations, synaptic weights did not change homogeneously and seemed to reflect patterns of the external perturbations applied to the model. In contrast, in the sleep mode, the authors implemented a modulation of the learning rule favoring depression that in concert with the high synchronicity of neuronal firing and the dynamics of the slow-wave activity produced a net reduction of the synaptic weights. Considering previous observation that in simulation the changes in synaptic weights were sufficient to promote the transition between sleep and waking states, the researchers could now implement and produce an autonomous sleep-awake cycle only controlled by the changes caused by plasticity. Namely, during waking, the net gain in synaptic weights augments cortical-cortical synchrony and produces slow-wave activity. During sleep, however, the 
Table 1

Computational models of the homeostasis theory. List of the different computational studies that present evidence taken from simulations in favor of SHY. Displayed with name first author and year, the name of the article and a short description. Separated by (a) models of SWS dynamics and (b) models of SWS and plasticity.

\begin{tabular}{|c|c|c|c|}
\hline & Authors & Computational model & Description \\
\hline \multirow[t]{5}{*}{ (a) } & $\begin{array}{l}\text { Bazhenov et al. } \\
\text { (2002) }\end{array}$ & $\begin{array}{l}\text { Model of Thalamocortical Slow-Wave Sleep Oscillations } \\
\text { and Transitions to Activated States }\end{array}$ & $\begin{array}{l}\text { The model describes features of SWS and activated states (such as } \\
\text { REM sleep or waking) in the thalamocortical system as well as the } \\
\text { transition between UP and Down states }\end{array}$ \\
\hline & Compte et al. (2003) & $\begin{array}{l}\text { Cellular and Network Mechanisms of Slow Oscillatory } \\
\text { Activity }(<1 \mathrm{~Hz}) \text { and Wave Propagations in a Cortical } \\
\text { Network Model }\end{array}$ & $\begin{array}{l}\text { A model for the slow oscillations observed in vitro that reproduces the } \\
\text { single neuron behaviors and the membrane potential oscillation } \\
\text { between UP and DOWN states. The model also describes a network } \\
\text { firing patterns in the control condition, as well as under } \\
\text { pharmacological manipulations like neuromodulators }\end{array}$ \\
\hline & $\begin{array}{l}\text { Hill and Tononi } \\
\text { (2005) }\end{array}$ & $\begin{array}{l}\text { Modeling Sleep and Wakefulness in the Thalamocortical } \\
\text { System }\end{array}$ & $\begin{array}{l}\text { The model is the first to integrate intrinsic neuronal properties with } \\
\text { detailed thalamocortical anatomy and to reproduce neural activity } \\
\text { patterns in both wakefulness and sleep, thereby providing a powerful } \\
\text { tool to investigate the role of sleep in information transmission and } \\
\text { plasticity }\end{array}$ \\
\hline & Esser et al. (2007) & $\begin{array}{l}\text { Sleep Homeostasis and Cortical Synchronization: I. } \\
\text { Modeling the Effects of Synaptic Strength on Sleep Slow } \\
\text { Waves }\end{array}$ & $\begin{array}{l}\text { The simulation used the thalamocortical model developed by Hill and } \\
\text { Tononi (2005) to explore the relationship between synaptic strength } \\
\text { and slow-wave activity and shows that cortical synaptic strength is } \\
\text { sufficient to account for changes in slow-wave activity during sleep, } \\
\text { with corresponding changes in slow wave parameters }\end{array}$ \\
\hline & $\begin{array}{l}\text { Esser, Hill, and } \\
\text { Tononi (2009) }\end{array}$ & $\begin{array}{l}\text { Breakdown of Effective Connectivity During Slow Wave } \\
\text { Sleep: Investigating the Mechanism Underlying a Cortical } \\
\text { Gate Using Large-Scale Modeling }\end{array}$ & $\begin{array}{l}\text { The model incorporates in the previous model (Hill \& Tononi, 2005) } \\
\text { basic principles of thalamocortical architecture, cellular and synaptic } \\
\text { physiology, and the influence of various arousal promoting } \\
\text { neuromodulators to understand the mechanisms underlying a } \\
\text { cortical gate }\end{array}$ \\
\hline $\begin{array}{l}\text { Komarov belongs } \\
\text { in (a) above }\end{array}$ & Komarov et al. (2018) & $\begin{array}{l}\text { A new class of reduced computationally efficient neuronal } \\
\text { models for large-scale simulations of brain dynamics }\end{array}$ & $\begin{array}{l}\text { Large-scale simulation of a cortical network. Simulations replicates } \\
\text { previous SWS features such as cortical UP and DOWN states and } \\
\text { transition between sleep and awake states. First model to show } \\
\text { travelling waves during sleep. Evaluates the role of synaptic noise in } \\
\text { the generation of replay sequences }\end{array}$ \\
\hline \multirow[t]{5}{*}{ (b) } & Olcese et al. (2010) & Sleep and synaptic renormalization: a computational study & $\begin{array}{l}\text { The model included a STDP rule in their simulations to show that the } \\
\text { synaptic changes induced during waking are preferably reactivated } \\
\text { during sleep, with a decrease in the incidence of reactivation as sleep } \\
\text { progresses. The model of sleep-dependent synaptic renormalization } \\
\text { leads to increased signal-to-noise ratios, increased resistance to } \\
\text { interference, and desaturation of learning capabilities }\end{array}$ \\
\hline & $\begin{array}{l}\text { Lubenov and Siapas } \\
\text { (2008) }\end{array}$ & $\begin{array}{l}\text { Decoupling through Synchrony in Neuronal Circuits with } \\
\text { Propagation Delays }\end{array}$ & $\begin{array}{l}\text { The simulations show that, in a recurrent network with delayed } \\
\text { connections and a STDP learning rule, synchronous activity leads to a } \\
\text { decoupling force whereas random activity promotes changes in the } \\
\text { synaptic weights that favors synchrony of activity }\end{array}$ \\
\hline & $\begin{array}{l}\text { Nere, Hashmi, Cirelli, } \\
\text { and Tononi (2013) }\end{array}$ & $\begin{array}{l}\text { Sleep-dependent synaptic down-selection (I): modeling the } \\
\text { benefits of sleep on memory consolidation and integration }\end{array}$ & $\begin{array}{l}\text { Biologically-constrained models considered explicit learning } \\
\text { paradigms - object recognition and motion anticipation - to test the } \\
\text { potential benefits for learning of synaptic depression during sleep }\end{array}$ \\
\hline & Hashmi et al. (2013) & $\begin{array}{l}\text { Sleep-Dependent Synaptic Down-Selection (II): Single- } \\
\text { Neuron Level Benefits for Matching, Selectivity, and } \\
\text { Specificity }\end{array}$ & $\begin{array}{l}\text { Simulations of sleep-dependent synaptic down-selection to } \\
\text { demonstrate the single-neuron level benefits for matching between } \\
\text { brain and environment, used to measure how this process increases } \\
\text { the ability of the neuron to capture environmental regularities, and } \\
\text { contributes to the selectivity of neuronal responses, and the } \\
\text { specificity across different neuronal subsets }\end{array}$ \\
\hline & $\begin{array}{l}\text { Sullivan and de Sa } \\
\text { (2008) }\end{array}$ & $\begin{array}{l}\text { Sleeping our way to weight normalization and stable } \\
\text { learning. }\end{array}$ & $\begin{array}{l}\text { A homeostatic synaptic scaling algorithm for abstract self-organizing } \\
\text { maps, to neutralize the unconstrained growth of Hebbian learning }\end{array}$ \\
\hline
\end{tabular}

slow-wave activity gradually reduces synaptic weights, which has a dampening effect on the slow-wave activity itself. The long-term effect on the net synaptic strength is neutral. The most remarkable feature of the simulations was that the sequences of neuronal activity that surged during the waking state were more likely to reappear in the sleep state. The chance of re-occurrence of these sequences dramatically decayed as synaptic depression advanced during sleep. The simulations produced computational evidence that synaptic plasticity and sleep/waking activity profiles interact so as to produce a stable cyclic dynamics across the sleep-wake cycle. Another study evaluated in detail the possible mechanisms that can link slow-wave sleep and synaptic depolarization considering a STDP rule in a recurrent network with conduction delays (Lubenov \& Siapas, 2008). Simulations revealed that in condition in which network activity is synchronized and exhibit population bursts, STDP rules promote synaptic changes that desynchronize activity. In contrast, with random network activity patterns, the learning rule promotes coupling and synchronization of activity.

The studies mentioned above did not produce any computational support for the behavioral advantage of sleep-evoked synaptic changes other than a renormalization function able to "keep the system working." To produce functional evidence, some studies considered explicit learning paradigms, such as object recognition and motion anticipation, to test the potential cognitive benefits of synaptic depression during sleep (Hashmi, Nere, \& Tononi, 2013; Nere, Olcese, Balduzzi, \& Tononi, 2012, 2013). The simulations demonstrated that activity-dependent synaptic potentiation during waking followed by off-line synaptic depression during sleep has a beneficial effect on the integration of new memories to the old ones and gist extraction (i.e. the identification of common features in a set of new items). One interesting analysis of the authors included a differentiation of the possible functional mechanisms of sleep-dependent learning at the network and cellular levels. The studies provide computational evidence that both network features, such as patterns of cortical-cortical connections, and cellular features, such as local synaptic patterns, benefit from the processes described by SHY. Altogether, these studies provide computational evidence that the SHY prediction of functional advantage after a 
renormalization cycle is mechanistically plausible.

It is also worth mentioning a completely different approach, unconcerned with detailed biophysics, to seek computational support for the behavioral consequences of SHY. Sullivan and de Sa (2008) applied a homeostatic synaptic scaling algorithm for abstract self-organizing maps to contrast with the "standard normalization of weights" often used to neutralize the unconstrained growth of Hebbian learning (Sullivan \& de Sa, 2006). Self-organizing maps are an artificial neural network formation used for unsupervised feature learning from an input dataset (Kohonen, 1982). "Standard normalization" cares about the net average of synaptic weights as individual synaptic weights change. The online normalizing rule applied commonly in machine learning models contrasts with an SHY-based normalizing rule that ignores synaptic normalization during learning and predicts an offline separate process for weight renormalization. The simulations demonstrate that both approaches lead to similar results in machine learning tasks. However, while the simulations validate the idea that an overall downscaling of synaptic weights can counteract the instability of Hebbian learning, the data also point to a possible caveat of SHY. If potentiation is disproportionally strong, and depending on the learning and normalizing dynamics, Hebbian learning can potentially saturate synaptic weights during waking, long before sleep ever takes place, which relates to the cognitive effect of learning saturation. Still, since the model has no link to quantitative biophysics, such warning could not be tested.

\section{Computational studies of memory reactivation during sleep}

The second class of sleep-dependent plasticity models proposes that the reactivation during sleep of memory traces acquired through waking experience supports the consolidation of such memories (Table 2). This view stems from the fact that sleep, and in particular SWS, promotes the replay of cortical-hippocampal activity related to memory encoding and consolidation (Chauvette et al., 2012; Ji \& Wilson, 2007; O’Neill, Pleydell-Bouverie, Dupret, \& Csicsvari, 2010; Pavlides \& Winson, 1989; Peyrache, Khamassi, Benchenane, Wiener, \& Battaglia, 2009; Ribeiro et al., 2004; Sejnowski \& Destexhe, 2000; van de Ven, Trouche, McNamara, Allen, \& Dupret, 2016; Wilson \& McNaughton, 1994). Most of the evidence in this direction comes from intracerebral electrophysiological recordings in rats, but molecular experiments in mice and human brain imaging studies also support this view (Abel, Havekes, Saletin, \& Walker, 2013). Replay theory proposes that the repetition during sleep of neuronal activity first experienced during waking reinforces some, but not all, synaptic patterns. Although different researchers hold distinct views of how this replay takes place and affects memories (Khodagholy, Gelinas, \& Buzsáki, 2017; Nádasdy et al., 1999; Pavlides \& Winson, 1989; Peyrache et al., 2009; Ribeiro et al., 2004; Tatsuno, Lipa, \& McNaughton, 2006; van de Ven et al., 2016; Wilson \& McNaughton, 1994), this group believes that sleep promotes remembering.

The first class of computational studies relevant to the reactivation theories intends to explain the mechanistic origin of the replay of neuronal activity observed during sleep (Table 2a). The spontaneous reactivation of experience-specific patterns of neuronal activity was first observed in extracellular recordings from the rat hippocampus (Pavlides \& Winson, 1989; Wilson \& McNaughton, 1994), therefore it is natural that the first models of the replay theory evoked mechanisms based on hippocampal models (Shen \& McNaughton, 1996). In this early model, each neuron represented a single position in 2-dimensional space, to emulate the activity response of place cells (O'Keefe \& Dostrovsky, 1971). The network simulated an awake exploration of the environment by using a Hebbian learning rule to reinforce the connections between neurons whose respective places overlapped. Sleep was simulated by adding random inputs to the neuronal population. During simulated sleep, the authors observed moments of low activity interleaved with brief events of high-frequency activity. The cells that were activated during exploration had a higher chance of being reactivated during sleep and tended to fire together with cells with overlapping reference places. A similar model produced equivalent results but considering areas adjacent to the hippocampus, such as the entorhinal cortex and the post-subiculum (Hasselmo, 2008). In models with a more comprehensive set of biophysical details (Jahnke, Timme, \& Memmesheimer, 2015; Molter, Sato, \& Yamaguchi, 2007), the authors could evaluate mechanisms underlying replay events, such as sharp-wave ripples (Buzsáki, 1986, 2015). The simulations indicate that the formation of fast sequences can be explained by the nonlinear amplification of synchronous inputs to the hippocampus, considering a random, rapid, and irregular sub-threshold input component, in concert with selective place cell activations. The mechanisms described in these studies point to the origin of the replay events well within the hippocampus (CA1/CA3), and can account for characteristic electrophysiological features of sharp-wave ripples such as LFP waveforms and the oscillation frequency profile. Remarkably, one crucial aspect of the sequences produced is that they are not necessarily equal to the experienced ones. This reflects the idea that different experiences lived during waking might overlap and interfere with each other, imposing a generalized hippocampal representation of the two memories (Berens \& Bird, 2017), or explaining why an adjacent map-like relational structure, such as the entorhinal cortex, might be interpolating multiple experiences in the form of novel sequences (Sanders, Rennó-Costa, Idiart, \& Lisman, 2015). A possible implication is that interference of new relations could potentially arise from such non-experienced sequences. Interestingly, memory reactivation could also be obtained with the thalamocortical models used to study synaptic downscaling during sleep (Olcese et al., 2010), indicating that memory replay can arise in different networks.

The second class of computational studies relevant to reactivation theories focuses on the mechanisms by which the reactivation of memory traces during sleep affects memory consolidation (Table 2b). Different computational studies considered abstract memory systems to evaluate how the reactivation of memory traces could enhance encoding, storage, and retrieval. Pioneer in such functional studies, Willian Levy investigated in a series of computational studies the role of online and offline sequences in the consolidation of memories in networks with hippocampal characteristics such as sparsity and recurrence (August \& Levy, 1999; Levy, 1996; Levy, Hocking, \& Wu, 2005; Minai \& Levy, 1993). Among these studies, it is of special interest for sleep research the simulations that demonstrate how the compact sequences of experienced can emerge from these networks (August \& Levy, 1999) and how the production of such compressed sequences can support cognitive function associated with the hippocampus such as the production of representations that can be easily readable by other networks and the support to neocortical encoding of memories (Levy et al., 2005).

In another model, Johnson and Redish (2005) studied the effect of memory reactivation on the processes of encoding and recalling of sequences memories in a functional abstract model inspired by the hippocampus network. Neurons in the network had a specific selectivity to places in a maze. In their model, an agent could predict the correct path to leave a maze after learning a path through a reinforcement learning paradigm. By adding a "sleep state" in which the replay of memory sequences drove network activity and consequently learning, the authors could accelerate the learning of the correct path. The algorithm provides a fast learning tool for conditions in which the sampling of experiences is rare or costly.

In a different model, the authors evaluated an unsupervised learning network that extracts image features (Hinton, Dayan, Frey, \& Neal, 1995). In contrast to the network constructed by the model above, which had neurons organized in a single layer with lateral connectivity, the network in this study considered many neuronal sheets with feedforward connectivity. In the waking state, many input samples were presented to the network in such a way that the activity propagated 
Table 2

Computational models of the replay theory. List of the different computational studies that present evidence taken from simulations in favor of Replay theory. Displayed with name first author and year, the name of the article and a short description. Separated by models of (a) dynamics of replay activation, (b) memory consolidation dependent on replay events and (c) complementary learning systems.

\begin{tabular}{lll}
\hline & Author & Computational model \\
\hline (a) & $\begin{array}{l}\text { Shen and McNaughton } \\
\text { (1996) }\end{array}$ & $\begin{array}{l}\text { Modeling the spontaneous reactivation of experience-specific } \\
\text { hippocampal cell assembles during sleep }\end{array}$
\end{tabular}
(1996)

Molter et al. (2007)

Hasselmo (2008)

Jahnke et al. (2015) A Unified

Temporally structured replay of neural activity in a model of the entorhinal cortex, hippocampus and post-subiculum

Reactivation of behavioral activity during sharp waves: a computational model for two state hippocampal dynamics.

(b) Alvarez and Squire (1994)

McClelland et al. (1995)
August and Levy (1999)

Norman et al. (2005)

hnson and Redish (2005)

Kirkpatrick et al. (2017)

(c) Wittenberg et al. (2002)
Memory consolidation and the medial temporal lobe: A simple network model

Why there are complementary learning systems in the hippocampus and neocortex: insights from the successes and failures of connectionist models of learning and memory

The "wake-sleep" algorithm for unsupervised neural networks

Temporal Sequence Compression by an Integrate-and-Fire Model of Hippocampal Area CA3

Methods for reducing interference in the Complementary Learning Systems model: oscillating inhibition and autonomous memory rehearsal

Hippocampal replay contributes to within session learning in a temporal difference reinforcement learning model

Overcoming catastrophic forgetting in neural networks

Synaptic reentry reinforcement based network model for long-term memory consolidation
Description

The network simulates an awake exploration of the environment by using a Hebbian learning rule to reinforce the connections between neurons whose respective places overlap. Sleep was simulated by adding random inputs to the population of neurons. During simulated sleep, the authors observed moments of low activity interleaved with brief events of high-frequency activity. The cells that were activated during exploration had a higher chance of being reactivated during sleep, and tended to fire together with cells with overlapping reference places

A computational model of the hippocampus with theta phase precession and synaptic plasticity during theta rhythm. Two mechanisms are proposed to initiate sharp-wave ripple events: random reactivation in the presence of rapid, irregular sub-threshold inputs and place selective cell activations. In 2D navigation computational experiments, rather than observing the perfect replay of experienced pathways, new pathways "experienced during immobility" emerge. This suggests a neural mechanism for shortcut navigation

The spiking activity of hippocampal neurons during rapid eye movement (REM) sleep exhibits temporally structured replay of spiking occurring during previously experienced trajectories. Here, temporally structured replay of place cell activity during REM sleep is modeled in a large-scale network simulation of grid cells, place cells and head direction cells The simulations indicate that nonlinear amplification of synchronous inputs in the hippocampus, considering a random, rapid, and irregular subthreshold input component, in concert with place selective cell activations explains the formation of fast sequences. The mechanisms described in these studies can also point to the origin of the replay events in the interior parts of the hippocampus (CA1/CA3) and can account for characteristic electrophysiological features of sharp-wave ripples such as LFP waveform and the oscillation frequency profile. Remarkably, one crucial aspect of the produced sequences is that they are not necessarily equal to the experienced ones

A simple neural network that modeled the memory consolidation process in such a way that memory is first stored in fast memory system (medial temporal lobe) during waking. Later, the memory trace is transferred to the others areas of the brain

They modeled the memory consolidation process like a Complementary Learning System in such a way that memory is first stored in a soft and fast memory system (hippocampus) during waking. Later, the memory trace is transferred to the hard memory system (neocortex) during sleep An unsupervised learning network that extracts image features. This study considered a network of many neuronal sheets with feed-forward connectivity. In the waking state, many input samples were presented to the network in such a way that the activity propagated from the bottom layers to the top. In the sleep state, activity in the upper layer was artificially set, simulating a replay signal that propagates back from top to bottom and that could artificially reproduce the original image in the input vector

Model of a simple network inspired by the hippocampal CA3 region that exhibit the formation of compact sequences of memories traces experienced during awake state

The model considers that SWS and REM contribute in a more specific way to the learning during the sleep: SWS contributes the hippocampal repetition of new memories in the cortex and REM supports tuning of pre-existing cortical and hippocampal. Reduction of memory interference can be obtained by a system set to strengthen the old memories that are relevant and to weaken those that interfere with it

The model was developed based on reinforcement learning. The model provides testable predictions relating the effects of hippocampal inactivation as well as hippocampal replay on this task

A solution based on memory replay that doesn't require the use of complementary learning systems if it only considers the labeling of relevant synapses for a memory in the learning of new ones. The model does not explicitly emulate sleep but describes abstract mechanisms that can reflect a function of sleep related dynamics such as memory trace replay

The model describes the consolidation mediated by the repeated postlearning reinforcement of synaptic modifications through hippocampus and cortex, it holds that memory reactivation during the sleep can also influence the process of memory selection. The study treated the temporal aspect, showing the despite the occurrence of an intrinsic destruction of the synaptic effectiveness throughout the week, and beyond, SRR is capable of strengthening and maintaining memory traces, where they would otherwise become unstable over time. They built a computational model to further 
Table 2 (continued)

\begin{tabular}{|c|c|c|}
\hline Author & Computational model & Description \\
\hline & & $\begin{array}{l}\text { illustrate and explore the effect of the SRR process on the formation of long- } \\
\text { term memory }\end{array}$ \\
\hline Káli and Dayan (2004) & $\begin{array}{l}\text { Off-line replay maintains declarative memories in a model of } \\
\text { hippocampal-neocortical interactions }\end{array}$ & $\begin{array}{l}\text { A computational study that investigated the storage, access and decoding of } \\
\text { episodic and semantic memories in hippocampal-cortical networks found } \\
\text { that replay plays an essential role in the maintenance and preservation of } \\
\text { stored traces. The model replicates in simulation the findings that recently } \\
\text { acquired memories are more prone to forgetting than old memories, as } \\
\text { episodic memories become semantic concepts. In the absence of } \\
\text { hippocampal reactivation, memory traces once considered stable and } \\
\text { consolidated are easily lost in the face of cortical plasticity }\end{array}$ \\
\hline Amaral et al. (2008) & $\begin{array}{l}\text { A Synaptic Reinforcement-Based Model for Transient Amnesia } \\
\text { Following Disruptions of Memory Consolidation and Reconsolidation }\end{array}$ & $\begin{array}{l}\text { The model provides means for fast recovery of memories in local networks } \\
\text { and serves as a computational explanation for events such as transient } \\
\text { amnesia "following disruptions of consolidation and reconsolidation." }\end{array}$ \\
\hline $\begin{array}{l}\text { Fiebig and Lansner } \\
\text { (2014) }\end{array}$ & $\begin{array}{l}\text { Memory consolidation from seconds to weeks: a three-state neural } \\
\text { network model with autonomous reinstatement dynamics. }\end{array}$ & $\begin{array}{l}\text { Proposed a functional neural network implementation of spontaneous } \\
\text { reactivations of hippocampal memories, as observed in place cell } \\
\text { reactivations during slow-wave-sleep. The model is an extended three-state } \\
\text { implementation of the CLS framework using a consolidation chain of } \\
\text { Bayesian Confidence Propagation Neural Networks, capable of autonomous } \\
\text { replay }\end{array}$ \\
\hline Wei et al. (2016) & $\begin{array}{l}\text { Synaptic Mechanisms of Memory Consolidation during Sleep Slow } \\
\text { Oscillations }\end{array}$ & $\begin{array}{l}\text { Computational model of the thalamocortical system to report that } \\
\text { interactions between slow cortical oscillations and synaptic plasticity } \\
\text { during deep sleep can underlie the mapping of hippocampal memory traces } \\
\text { to persistent cortical representation }\end{array}$ \\
\hline Lerner (2017) & Unsupervised Temporal Learning During Sleep Supports Insight & $\begin{array}{l}\text { The core of the model is that compressed memory replay in the } \\
\text { hippocampus bring disparate encoded events "together" to allow detecting } \\
\text { hidden temporal regularities within stimuli that were too separate in time } \\
\text { during wake (over seconds) to be detected by Hebbian mechanisms. This } \\
\text { allows, as a second stage, for predicting upcoming events by the prefrontal } \\
\text { cortex during the following wake period (through wake replay that serves as } \\
\text { a 'cue' to elicit the full temporal representations discovered by the } \\
\text { hippocampus during the prior sleep). The model thus directly relates to } \\
\text { results in the literature supporting an effect of SWS on insight (Fischer et al., } \\
\text { 2006; Wagner et al., 2004), which were all achieved in tasks containing } \\
\text { temporal regularities }\end{array}$ \\
\hline
\end{tabular}

from the bottom layers to the top. In the sleep state, activity in the upper layer was artificially set, simulating a replay signal that propagated back, from top to bottom, and that could artificially reproduce the original image in the input vector. The learning rule applied during the waking state sought to enhance the ability of the sleeping network to reproduce the original image. In contrast, the learning rule applied during the sleep state enhanced the ability of the awake network to differentiate the activity vector in the upper layers. By separating learning in two states, the authors could show that emerging representations in the feature space provide a very economic description of the input images. One might observe the difference in the network structure of the memory systems (horizontal vs. vertical) and the functional advance introduced by sleep (fast learning vs. better memory coding) when comparing this model with the one described in the previous paragraph. Such disparity provides evidence that the effect of sleep-dependent memory reactivation on learning might be multifactorial.

Other models considered a fundamental concept for the replay theory, namely the idea that the hippocampus and the neocortex form Complementary Learning Systems (CLS) (McClelland, McNaughton, \& O'Reilly, 1995; Squire, Stark, \& Clark, 2004) (Table 2c). The notion that the hippocampus and the neocortex have complementary roles derives from the fact that these regions have very different connections and underlie distinct functions. However, the specific function attributed to each region by the many available computational models is far from consensual. As an example, it was hypothesized that the hippocampus is a temporary memory store for new data while the neocortex served as a permanent memory store (Marr, 1971). In a similar direction, the overlapping (accelerated) replay of new memories during SWS has been implicated with the integration of a new memory encoded by the hippocampus into an existing neocortical memory schema (Lewis \& Durrant, 2011). The different roles for each brain region are not just related to time, but also to the generalization level attained by the memory trace stored. In humans, the interplay between the two regions favors the integration of episodic memories into semantic networks (Walker \& Stickgold, 2010). The hippocampus is also seen as a structure that can orient memory organization in the neocortex (Grossberg, 1976; Wickelgren, 1979), and orchestrate different areas of the cortex, by associating memories distributed far apart (Mishkin, 1982). There is a new consensus regarding the role of the hippocampus in the formation and retention of an index of neocortical areas activated by experiential events (Teyler \& DiScenna, 1986). Based on this notion, different studies modeled the memory consolidation process in such a way that memory is first stored in a soft and fast memory system (hippocampus) during waking. Later, during sleep, the memory trace is transferred to the hard memory system (neocortex) (Alvarez \& Squire, 1994; McClelland et al., 1995).

One of the functions hypothesized for having complementary learning systems such as the hippocampus and the neocortex is that they provide a solution for the problem of catastrophic forgetting in memory systems (Hasselmo, 2017). Catastrophic forgetting or catastrophic interference occurs when the learning of a new memory negatively interferes with the encoding of a memory learned in a previous occasion. Such destructive effect in learning only rarely happens in animals whereas, under certain circumstances, it is very common in connectionist networks (French \& French, 1999). The concept of catastrophic forgetting also relates to the idea of the "memory capacity" of a network. One network can only store memories to the limit by which catastrophic interference begins to occur (de Almeida, Idiart, \& Lisman, 2007).

CLS theory solves such issue as follows. New information is quickly encoded in a temporary store during the awake experience. During sleep (or waking) consolidation, old memories from a stable store are also loaded in the temporary store. Next, all memories, old and new, are 
interleaved used as the reference for an update of traces in the stable store. Since old and new memories are present altogether, the network can slowly find a synaptic organization that encompasses all the learned memories. Simulations that support this theory compared the performance differences in the encoding of memories in an artificial neural network when the input patterns were presented interleaved or separated (McClelland et al., 1995). The simulations demonstrated a considerable lower interference of new memories when old and new patterns were presented slowly and interleaved. Another computational study that implemented a similar network provided a similar account when considering a network that learns to represent visual patterns (Hattori, 2012). Importantly, the implementation of slow and fast learning components in a memory system does not necessarily depend on two networks, as proposed by CLS. An alternative considers different dynamic processes of learning within the synapses of the same network. As an example, one model combined fast and slow variables in the modeled synapses to show that the memory capacity of the network grows linearly with the number of synapses (Benna \& Fusi, 2016). In this specific model, fast and slow synapses within the same neuron interact bi-directionally as new patterns are presented to the network. Although this model does not specifically address sleep, it describes well the functioning of CLS in a computational model. It seems a reasonable extension to consider non-uniform learning rates and transmission between synaptic types in the emulation of sleep stages. It remains to be verified whether the capacity scalability of the network would remain linear across sleep stages.

A concept closely related to the catastrophic forgetting issue and usually considered by the propositions that seek a solution to the problem is the "stability and plasticity" dilemma (Carpenter \& Grossberg, 1988). The decision that must be made by a learning algorithm when considering new information is whether the new memory should be allowed to affect the current structure, with the potential of disrupting old memories, or whether it should not, at the risk of not encoding something relevant. The use of CLS offers a practical solution for the dilemma when considering functionalities other than the off-line interleaved replay (Norman, Newman, \& Perotte, 2005). The proposed system uses local oscillations based on feedback inhibition to identify components of a memory trace that are weakly stored, and should be strengthened, and components of other memory traces that compete with it and that should be weakened. Another mechanism involves local processes within the cortex and the hippocampus such as the adaptation of current patterns to one previously stored (pattern completion). Simulation data show that a multitude of mechanisms in the CLS provides better memory capacity in the condition that is known to provoke memory interference. Furthermore, a similar solution based on memory replay might not require the use of CLS if it only considers the labeling of relevant synapses for a memory in the learning of new ones (Kirkpatrick et al., 2017). In the latter model, relevant synapses are protected from modification once a new pattern is presented, so that it only affects synapses that are not relevant to the memories already known.

Other models investigated the importance of local computation within the hippocampus or the neocortex for the interplay between these areas during consolidation, taking into consideration critical biophysical details such as the dynamics of protein formation. The concept of synaptic reentry reinforcement proposes that local replay can repeatedly trigger the molecular cascade that leads to synaptic structuring, counteracting the rapid degradation of synaptic receptor proteins (Shimizu, Tang, Rampon, \& Tsien, 2000). In simulations of a computational model that implements this concept (Wittenberg, Sullivan, \& Tsien, 2002), the authors demonstrated a transfer of memory traces from the hippocampus to the cortex. The transfer theory posits that episodic memories migrate from the hippocampus to become semantic memories in the cortex. Since cortical areas comprise synaptic connections across sensory areas, such transfer theoretically leads to faster processing of sensory inputs. The model provides means for the fast recovery of memories in local networks, and serves as a computational explanation for events such as transient amnesia (i.e. temporary inability to establish new memories).

Understanding transient amnesia may or may not be directly relevant for the sleep and memory field, but the fact that models based on CLS provide a mechanistic explanation for this effect indicates that the theory captures essential aspects of the brain network. In an emerging consensus, learning results from the combination of activity-dependent plasticity, systems consolidation and the capacity for storing manifold, multiplexed and often competing memory traces (Amaral, Osan, Roesler, \& Tort, 2008). A computational study that investigated the storage, access, and decoding of episodic and semantic memories in hippocampal-cortical networks found that replay plays an essential role in the maintenance and preservation of stored traces (Káli \& Dayan, 2004). The model replicated in simulation the finding that recently acquired memories are more prone to forgetting than old memories, as episodic memories become semantic concepts. In the absence of hippocampal reactivation, memory traces once considered stable and consolidated were easily lost in face of cortical plasticity. This suggests that hippocampal replay allows the memory system to refresh the record of connections between hippocampal and cortical representations, maintaining them in register despite the changes in the cortical network.

An important aspect of the cortical-hippocampus systems is the form of the memory trace. The sequential and orthogonal nature of the hippocampal representation (Lisman \& Jensen, 2013) differs from the persistent and distributed structure verified in cortical networks (Steriade, Timofeev, \& Grenier, 2001), especially during the UP and DOWN states characteristics of slow-wave activity in the neocortex (Bazhenov et al., 2002). The question that arises is how do the two different codes interact? One computational model considered the different natures of the hippocampal and neocortical codes and showed that local reactivation in a thalamocortical network could interact with hippocampal-like ripples resulting in input-specific changes of synaptic weights (Wei, Krishnan, \& Bazhenov, 2016). In the simulations of the model, the spatiotemporal pattern of activity propagation in the UP state regulates the changes of synaptic strengths between neurons, indicating a specific role for the different states of slow-wave activity and a potential role for the coincidence of neocortical states and the occurrence of hippocampal ripples. These results relate to the observation that changes in neocortical states precede replay events (Rothschild, Eban, \& Frank, 2017) and are aligned with the concept that the neocortex can sculpt the patterns of hippocampal activity that can pass through, known as the cortical gate function (Lewis \& Durrant, 2011; Peyrache, Battaglia, \& Destexhe, 2011). The ability of the neocortex to interfere in the hippocampus representation can support the formation of shared schemas primarily stored at the cortex, but updated by new information with the hippocampal interaction.

Another model to consider the differences in neocortical and hippocampal coding posits a temporal scaffolding function for the observed coding differences (Lerner, 2017a). In such a model, the function of the time compression of sequences in the hippocampus is to overcome a limitation of molecular mechanisms underlying Hebbian learning for sequential patterns separated by intervals in the "seconds" range. The role of the hippocampus is to reorganize these memory sequences perceived in a "long" time scale into a time frame adequate to cortical learning. In a computational implementation of this principle with a spiking neural network model of the hippocampus and prefrontal cortex, simulations demonstrated that the supervised learning of sequential patterns in the cortex benefits from the sleep-dependent unsupervised learning in the hippocampus in a forward predictive task (Lerner, 2017b). It is worth mentioning another computational model that implements the transfer theory and tackles the temporal scaffolding function (Fiebig \& Lansner, 2014). The model, which included a differentiation between sensory driven cortical areas and the prefrontal cortex, produced the stochastic reactivation dynamics of replay and 
consolidated episodic memory in a pattern learning protocol. Interestingly, the model exhibited typical empirical memory effects such as retrograde and anterograde amnesia after simulated hippocampal impairment, and replicated the detrimental effects of benzodiazepines on memory.

\section{Computational investigation of theories based on different roles for the different states of sleep}

An alternative concept to the apparently conflicting roles of strengthening or weakening memory traces during sleep is proposed by the sequential theory, which postulates that the different sleep states play distinct but complementary cognitive roles: While SWS would weaken irrelevant or competing synaptic patterns, REM sleep would strengthen the relevant ones (Giuditta et al., 1995; Giuditta, 2014). Mechanistic insight regarding this perspective came from evidence of experience-dependent IEG upregulation during REM sleep in the hippocampus and cerebral cortex of rodents, including transcription factors Zif-268, CREB and Fos, phosphatases Ppp2ca and Ppp2r2d, and cytoskeleton-associated gene Arc (Calais, Ojopi, Morya, Sameshima, \& Ribeiro, 2015; Ravassard et al., 2009; Ribeiro, Goyal, Mello, \& Pavlides, 1999, 2002, 2007; Ulloor \& Datta, 2005). REM sleep also promotes the experience-dependent phosphorylation of Calcium/Calmodulin-Dependent Protein Kinase type II (CaMKII) (Blanco et al., 2015), a key component of the molecular cascade that leads to LTP (Silva, Stevens, Tonegawa, \& Wang, 1992), responsible for sustained levels of phosphorylation in the early steps of the signaling cascade (Mayford et al., 1996; Silva et al., 1992). Altogether, these molecules are involved in various aspects of synaptic remodeling.

The experiments that led to these results were overall similar to those used to support SHY, but with two important differences. Firstly, SWS and REM sleep were scrupulously separated using electrophysiological markers. Secondly, non-stimulated animals were compared to animals exposed to new sensory and/or motor stimuli. The results showed that SWS effectively downregulates the levels of plasticity-related factors, regardless of the animal's prior experience. REM sleep, on the other hand, has distinct effects depending on the animal's previous experience. In non-exposed animals, REM sleep downregulates IEG expression, but in exposed animals REM sleep induces the transcription of the same genes.

This line of research led to the synaptic embossing theory, which proposes that the sleep stages other than REM (NREM) harbor both Hebbian synaptic upscaling (due to trace reverberation) and nonHebbian synaptic downscaling (due to homeostatic plasticity), while REM sleep triggers Hebbian long-lasting plasticity able to strengthen and weaken complementary circuits, respectively tagged or untagged by relevant waking experience (Poe, Walsh, \& Bjorness, 2010; Ribeiro \& Nicolelis, 2004; Ribeiro, 2012; Stickgold, Whidbee, Schirmer, Patel, \& Hobson, 2000). Experimental support for the embossing theory in humans comes from the observation that the product of the amount of early SWS and late REM can explain $80 \%$ of the variance in the performance improvement in a visual task (Stickgold et al., 2000). The predictions made by the embossing theory are overall similar to those made by the theory of active systems consolidation during sleep, which assumes however that memory consolidation at the systems level occurs exclusively during SWS, while REM sleep would solely promote local synaptic plasticity (Born \& Wilhelm, 2012).

Unlike the other two classes of theories described in the sections above, the computational evidence for the two-stage hypothesis is restricted to a single study which implemented two different models aimed at providing predictive and functional evidence for the synaptic embossing theory (Blanco et al., 2015). The first model implemented was an abstract neural network with connections subject to an STDP learning rule (van Rossum, Bi, \& Turrigiano, 2000) and an independent reactivation pattern. The network was fed with data (action potentials) obtained from real recordings from the CA1 field of the hippocampus of rats, as they spontaneously traversed different states of sleep. It is interesting to notice that unlike other studies (e.g., Olcese et al., 2010), the instantaneous synaptic plasticity rule in this model is not modified by the ongoing sleep-wake state. The simulations demonstrated that the pattern of input activity during waking led to synaptic potentiation, whereas activity during SWS led to synaptic downscaling, as in SHY theory. The independent reactivation pattern produced LTP on selected weights a few hours after a triggering sleep event. After an evaluation of the different triggers of LTP, with reference to original immunohistochemistry data showing experience-dependent phosphorylation of CaMKII during REM sleep, the simulated data showed that using the transition between REM and SWS as a trigger for LTP rendered highest levels of synaptic reorganization if compared to other LTP triggers such as the end of SWS period. The results support a function for LTP in the restructuring of the synaptic landscape, in alignment with the embossing theory (Stickgold et al., 2000; Ribeiro \& Nicolelis, 2004; Poe et al., 2010; Ribeiro, 2012) as well as some aspects of the active system consolidation theory (Born \& Wilhelm, 2012).

In the same study, a second simulation used a canonical hippocampal model (de Almeida, Idiart, \& Lisman, 2009a, 2009b; RennóCosta \& Tort, 2017; Rennó-Costa, Lisman, \& Verschure, 2010, 2014) to study the ability of LTP to imprint a specific pattern in a network. The simulations demonstrated that a period of synaptic downscaling prior to a selective LTP period facilitates the modification of the network patterns by inputs from another network (Blanco et al., 2015). These simulated results indicate that the interaction between homeostasis and reactivation mechanisms can facilitate the reorganization of memory during sleep, with positive effects for learning.

\section{Discussion}

The sleep and memory field is very much alive as it continues to evolve from apparently incongruent findings to a new synthesis able to make sense of all the empirical evidence already available. Some of the core questions in the field remain open. For instance, why is sleep needed to weaken and strengthen synapses, if LTD and LTP both occur normally during waking, as in the example of self-organizing maps discussed above (Sullivan \& de Sa, 2006)? While the answer to this question relates directly to the biology of state-dependent synaptogenesis, computational models can help to understand the constraints posed on memory consolidation by online waking processing, which is characterized by retroactive interference and catastrophic forgetting.

Likewise, the need for a two-stage process within sleep (i.e. REM and NREM) remains an important focus of contention which cannot be solely solved by computational modeling, but that can certainly benefit from modeling the known specificities of these stages in search of necessary and sufficient features. The fact that REM sleep is suppressed by fear (Jha, Brennan, Pawlyk, Ross, \& Morrison, 2005) suggests that, under strong predation pressure, offline memory consolidation will be dominated by SWS, which favors both the forgetting of irrelevant information and the strengthening of relevant information, but fails to promote memory restructuring and therefore creativity. The two-stage model may therefore be applicable only to animals at the top of the food chain, where creativity is an affordable luxury.

At present, the conflicting theories of sleep and memory assessed by computational modeling cannot be discriminated based solely on their empirical ground. All three classes of synaptic modification proposed to occur during sleep, namely homeostasis, reactivation and two-stage classes of theories, are supported by computational evidence provided by modeling and simulation studies. Computational models of the homeostasis hypothesis show how neural networks can counteract the overall synaptic potentiation during waking with synaptic downscaling during sleep. This effect positively affects the storage and recall of memories acquired during waking, and normalizes synaptic weights to prepare the brain for new memories. Computational models of memory reactivation during sleep demonstrate that the observed replay of 
memory traces is a natural byproduct of learning during waking. Moreover, the continued learning during sleep, oriented by replay events, has important advantages for the reorganization of memory: it allows for the extraction of regularities from encoded experiences, the development of economic representations and for the integration of new memories with the pool of old memories. Finally, a model of the two-stage theory of sleep indicates that the initial stage of synaptic downscaling facilitates a subsequent stage of selective synaptic potentiation.

The significant challenge in building a model with realistic anatomical aspects is to find direct links between experimentally observable data and numerical variables. As an example, the level of activation and auto-phosphorylation of CaMKII has been used as a marker for synaptic plasticity (Blanco et al., 2015). Incorporating detailed models that can link the abstract concepts of changes in synaptic weights to levels of CaMKII activation provides a path to directly compare the simulated data with experimental values (Hashambhoy, Winslow, \& Greenstein, 2009; Holmes, 2000; Lisman \& Zhabotinsky, 2001; Lučić, Greif, \& Kennedy, 2008). The association is not always possible, either because the added complexity might make the simulations unfeasible, or because the underlying mechanisms are simply unknown. In such cases, approaches taken from areas such as systems biology might render data-driven realistic simplifications that can surpass both limitations (Kotaleski \& Blackwell, 2010). Moreover, the fast-paced evolution of parallel computer architectures and data collection allow large-scale simulations such as full-scale models of the hippocampus CA1 with regard to the number of neurons (Bezaire, Raikov, Burk, Vyas, \& Soltesz, 2016), or very detailed models of the neocortical microcircuit (Markram, 2015).

It is important to consider that the stark theoretical distinctions of two decades ago have been softened and nuanced over time. Proponents of the synaptic strengthening group allow that some degree of downscaling may be occurring during sleep (Diekelmann \& Born, 2010; Grosmark, Mizuseki, Pastalkova, Diba, \& Buzsáki, 2012). In turn, the main proponents of the SHY theory have conceded that a restricted set of synapses may be potentiated or spared from downscaling during sleep (Tononi \& Cirelli, 2014).

\section{Funding}

Support obtained from the Federal University of Rio Grande do Norte, Conselho Nacional de Desenvolvimento Científico e Tecnológico (CNPq) grants 308775/2015-5 and 408145/2016-1 to SR and 427575/ 2016-8 to CRC; Coordenação de Aperfeiçoamento de Pessoal de Nível Superior (CAPES-MINCyT) to SR; Fundação de Amparo à Pesquisa do Rio Grande do Norte grant Pronem 003/2011 to SR; Fundação de Amparo à Pesquisa do Estado de São Paulo grant \#2013/07699-0 Center for Neuromathematics to SR, Pew Latin American Fellows Program to SR, Google Latin America Research Award 2017 to CRC, ACC and SR.

\section{References}

Abel, T., Havekes, R., Saletin, J. M., \& Walker, M. P. (2013). Sleep, plasticity and memory from molecules to whole-brain networks. Current Biology, 23, R774-R788 Available at: http://linkinghub.elsevier.com/retrieve/pii/S0960982213008488 [Accessed January 12, 2018].

Abraham, W. C., Dragunow, M., \& Tate, W. P. (1991). The role of immediate early genes in the stabilization of long-term potentiation. Molecular Neurobiology, 5, 297-314 Available at: http://www.ncbi.nlm.nih.gov/pubmed/1688055 [Accessed January 4, 2018].

Alberini, C. M. (2009). Transcription factors in long-term memory and synaptic plasticity. Physiological Reviews, 89, 121-145 Available at: http://www.ncbi.nlm.nih.gov/ pubmed/19126756 [Accessed January 24, 2018].

Alvarez, P., \& Squire, L. R. (1994). Memory consolidation and the medial temporal lobe: A simple network model. Proceedings of the National Academy of Sciences of the United States of America, 91, 7041-7045 Available at: Http://www.ncbi.nlm.nih.gov/ pubmed/8041742 [Accessed January 15, 2018].

Amaral, O. B., Osan, R., Roesler, R., \& Tort, A. B. L. (2008). A synaptic reinforcement- based model for transient amnesia following disruptions of memory consolidation and reconsolidation. Hippocampus, 18, 584-601 Available at: http:// www.ncbi.nlm.nih.gov/pubmed/18306305 [Accessed January 15, 2018].

Arellano, J. I., Benavides-Piccione, R., Defelipe, J., \& Yuste, R. (2007). Ultrastructure of dendritic spines: Correlation between synaptic and spine morphologies. Frontiers in Neuroscience, 1, 131-143 Available at: Http://www.ncbi.nlm.nih.gov/pubmed/ 18982124 [Accessed January 4, 2018].

Armbruster, M., \& Ryan, T. A. (2011). Synaptic vesicle retrieval time is a cell-wide rather than individual-synapse property. Nature Neuroscience, 14, 824-826 Available at: http://www.nature.com/articles/nn.2828 [Accessed January 3, 2018].

Aton, S. J., Seibt, J., Dumoulin, M., Jha, S. K., Steinmetz, N., Coleman, T., ... Frank, M. G. (2009). Mechanisms of sleep-dependent consolidation of cortical plasticity. Neuron, 61, 454-466 Available at: http://www.ncbi.nlm.nih.gov/pubmed/19217381 [Accessed January 12, 2018].

August, D. A., \& Levy, W. (1999). Temporal sequence compression by an integrate-andfire model of hippocampal area CA3. Journal of Computational Neuroscience, 6, 71-90 Available at: http://link.springer.com/10.1023/A:1008861001091 [Accessed August 7, 2018].

Bao, J. X., Kandel, E. R., \& Hawkins, R. D. (1997). Involvement of pre- and postsynaptic mechanisms in posttetanic potentiation at Aplysia synapses. Science, 275, 969-973 Available at: http://www.ncbi.nlm.nih.gov/pubmed/9020078 [Accessed January 3, 2018].

Bazhenov, M., Timofeev, I., Steriade, M., \& Sejnowski, T. J. (2002). Model of thalamocortical slow-wave sleep oscillations and transitions to activated States. Journal of Neuroscience, 22, 8691-8704 Available at: http://www.ncbi.nlm.nih.gov/pubmed/ 12351744 [Accessed May 29, 2018].

Benna, M. K., \& Fusi, S. (2016). Computational principles of synaptic memory consolidation. Nature Neuroscience Available at: http://www.nature.com/doifinder/ 10.1038/nn.4401 [Accessed October 6, 2016].

Berens, S. C., \& Bird, C. M. (2017). The role of the hippocampus in generalizing configural relationships. Hippocampus, 27, 223-228 Available at: http://www.ncbi.nlm.nih.gov/ pubmed/27933668 [Accessed May 29, 2018].

Bezaire, M. J., Raikov, I., Burk, K., Vyas, D., \& Soltesz, I. (2016). Interneuronal mechanisms of hippocampal theta oscillations in a full-scale model of the rodent CA1 circuit. Elife, 5, e18566 Available at: https://elifesciences.org/articles/18566 [Accessed January 18, 2018].

Blanco, W., Pereira, C. M., Cota, V. R., Souza, A. C., Rennó-Costa, C., Santos, S., ... Ribeiro, S. (2015). Synaptic homeostasis and restructuring across the sleep-wake cycle. PLoS Computational Biology, 11, e1004241 Available at: http://journals.plos.org/ploscompbiol/article?id=10.1371/journal.pcbi.1004241 [Accessed May 29, 2015].

Bliss, T. V. P., \& Collingridge, G. L. (1993). A synaptic model of memory: Long-term potentiation in the hippocampus. Nature, 361, 31-39 Available at: Http:// www.ncbi.nlm.nih.gov/pubmed/8421494 [Accessed January 3, 2018].

Bliss, T. V. P., \& Lømo, T. (1973). Long-lasting potentiation of synaptic transmission in the dentate area of the anaesthetized rabbit following stimulation of the perforant path. Journal of Physiology, 232, 331-356 Available at: http://doi.wiley.com/10.1113/ jphysiol.1973.sp010273 [Accessed March 28, 2012].

Born, J., Rasch, B., \& Gais, S. (2006). Sleep to remember. Neurosciences, 12, 410-424 Available at: http://www.ncbi.nlm.nih.gov/pubmed/16957003 [Accessed January 3, 2018].

Born, J., \& Wilhelm, I. (2012). System consolidation of memory during sleep. Psychological Research, 76, 192-203 Available at: http://www.ncbi.nlm.nih.gov/ pubmed/21541757 [Accessed January 3, 2018].

Bosch, M., Castro, J., Saneyoshi, T., Matsuno, H., Sur, M., \& Hayashi, Y. (2014). Structural and molecular remodeling of dendritic spine substructures during long-term potentiation. Neuron, 82, 444-459 Available at: http://www.ncbi.nlm.nih.gov/ pubmed/24742465 [Accessed January 4, 2018].

Bozon, B., Kelly, A., Josselyn, S. A., Silva, A. J., Davis, S., \& Laroche, S. (2003). MAPK, CREB and zif268 are all required for the consolidation of recognition memory. Philosophical transactions of the Royal Society of London. Series B, Biological Sciences, 358, 805-814 Available at: http://www.ncbi.nlm.nih.gov/pubmed/12740127 [Accessed January 24, 2018].

Buzsáki, G. (1986). Hippocampal sharp waves: Their origin and significance. Brain Research, 398, 242-252 Available at: Http://www.ncbi.nlm.nih.gov/pubmed/ 3026567 [Accessed August 21, 2018].

Buzsáki, G. (2015). Hippocampal sharp wave-ripple: A cognitive biomarker for episodic memory and planning. Hippocampus, 25, 1073-1188 Available at: Http:// www.ncbi.nlm.nih.gov/pubmed/26135716 [Accessed January 5, 2018].

Calais, J. B., Ojopi, E. B., Morya, E., Sameshima, K., \& Ribeiro, S. (2015). Experiencedependent upregulation of multiple plasticity factors in the hippocampus during early REM sleep. Neurobiology of Learning and Memory, 122, 19-27 Available at: http://linkinghub.elsevier.com/retrieve/pii/S1074742715000052 [Accessed January 12, 2018].

Carpenter, G. A., \& Grossberg, S. (1988). The ART of adaptive pattern recognition by a self-organizing neural network. Computer (Long Beach Calif), 21, 77-88 Available at: http://ieeexplore.ieee.org/document/33/ [Accessed May 30, 2018].

Chauvette, S., Seigneur, J., \& Timofeev, I. (2012). Sleep oscillations in the thalamocortical system induce long-term neuronal plasticity. Neuron, 75, 1105-1113 Available at: http://linkinghub.elsevier.com/retrieve/pii/S0896627312008008 [Accessed January 12, 2018].

Chowdhury, S., Shepherd, J. D., Okuno, H., Lyford, G., Petralia, R. S., Plath, N., ... Worley, P. F. (2006). Arc/Arg3.1 interacts with the endocytic machinery to regulate AMPA receptor trafficking. Neuron, 52, 445-459 Available at: http://www.ncbi.nlm. nih.gov/pubmed/17088211 [Accessed January 24, 2018].

Chrobak, J. J., \& Buzsáki, G. (1994). Selective activation of deep layer (V-VI) retrohippocampal cortical neurons during hippocampal sharp waves in the behaving rat. 
Journal of Neuroscience, 14, 6160-6170 Available at: http://www.ncbi.nlm.nih.gov/ pubmed/7931570 [Accessed August 21, 2018].

Churchland, P. S., \& Sejnowski, T. J. (2016). Blending computational and experimental neuroscience. Nature Reviews Neuroscience, 17, 667-668 Available at: http:// www.nature.com/articles/nrn.2016.114 [Accessed January 15, 2018].

Cichon, J., \& Gan, W.-B. (2015). Branch-specific dendritic $\mathrm{Ca}^{2+}$ spikes cause persistent synaptic plasticity. Nature, 520, 180-185 Available at: http://www.ncbi.nlm.nih.gov/pubmed/25822789 [Accessed January 12, 2018].

Citri, A., \& Malenka, R. C. (2008). Synaptic plasticity: Multiple forms, functions and mechanisms. Neuropsychopharmacology, 33, 18-41 Available at: Http://www.nature.com/articles/1301559 [Accessed January 4, 2018].

Cole, A. J., Saffen, D. W., Baraban, J. M., \& Worley, P. F. (1989). Rapid increase of an immediate early gene messenger RNA in hippocampal neurons by synaptic NMDA receptor activation. Nature, 340, 474-476 Available at: http://www.ncbi.nlm.nih.gov/pubmed/2547165 [Accessed January 24, 2018].

Compte, A., Sanchez-Vives, M. V., McCormick, D. A., \& Wang, X.-J. (2003). Cellular and network mechanisms of slow oscillatory activity $(<1 \mathrm{~Hz})$ and wave propagations in a cortical network model. Journal of Neurophysiology, 89, 2707-2725 Available at: http://www.ncbi.nlm.nih.gov/pubmed/12612051 [Accessed May 29, 2018].

Crick, F., \& Mitchison, G. (1983). The function of dream sleep. Nature, 304, 111-114 Available at: http://www.ncbi.nlm.nih.gov/pubmed/6866101 [Accessed January 3, 2018].

Csicsvari, J., Hirase, H., Czurkó, A., Mamiya, A., \& Buzsáki, G. (1999). Fast network oscillations in the hippocampal CA1 region of the behaving rat. Journal of Neuroscience, 19, RC20 Available at: http://www.ncbi.nlm.nih.gov/pubmed/ 10436076 [Accessed August 21, 2018].

Davis, H. P., \& Squire, L. R. (1984). Protein synthesis and memory: A review. Psychological Bulletin, 96, 518-559 Available at: Http://www.ncbi.nlm.nih.gov/pubmed/6096908 [Accessed January 16, 2018].

de Almeida, L., Idiart, M., \& Lisman, J. E. (2007). Memory retrieval time and memory capacity of the CA3 network: Role of gamma frequency oscillations. Learning \& Memory, 14, 795-806 Available at: Http://www.ncbi.nlm.nih.gov/pubmed/ 18007022.

de Almeida, L., Idiart, M., \& Lisman, J. E. (2009b). The input-output transformation of the hippocampal granule cells: From grid cells to place fields. Journal of Neuroscience, 29, 7504-7512 Available at: Http://www.ncbi.nlm.nih.gov/pubmed/19515918.

de Almeida, L., Idiart, M., \& Lisman, J. E. (2009a). A second function of gamma frequency oscillations: An E\%-max winner-take-all mechanism selects which cells fire. Journal of Neuroscience, 29, 7497-7503 Available at: Http://www.ncbi.nlm.nih.gov/ pubmed/19515917.

de Vivo, L., Bellesi, M., Marshall, W., Bushong, E. A., Ellisman, M. H., Tononi, G., \& Cirelli, C. (2017). Ultrastructural evidence for synaptic scaling across the wake/sleep cycle. Science (80-), 355, 507-510 Available at: http://www.ncbi.nlm.nih.gov/ pubmed/28154076 [Accessed January 24, 2018].

Del Castillo, J., \& Katz, B. (1954). Statistical factors involved in neuromuscular facilitation and depression. Journal of Physiology, 124, 574-585 Available at: http:// www.ncbi.nlm.nih.gov/pubmed/13175200 [Accessed January 3, 2018].

Diekelmann, S., \& Born, J. (2010). The memory function of sleep. Nature Reviews Neuroscience, 11, 114-126 Available at: http://www.ncbi.nlm.nih.gov/pubmed/ 20046194 [Accessed May 18, 2017].

Donlea, J. M., Thimgan, M. S., Suzuki, Y., Gottschalk, L., \& Shaw, P. J. (2011). Inducing sleep by remote control facilitates memory consolidation in Drosophila. Science (80-), 332, 1571-1576 Available at: http://www.ncbi.nlm.nih.gov/pubmed/21700877 [Accessed May 31, 2018].

Dumoulin Bridi, M. C., Aton, S. J., Seibt, J., Renouard, L., Coleman, T., \& Frank, M. G. (2015). Rapid eye movement sleep promotes cortical plasticity in the developing brain. Science Advances, 1, e15001055 Available at: http://advances.sciencemag.org/ cgi/doi/10.1126/sciadv.1500105 [Accessed January 12, 2018].

Esser, S. K., Hill, S. L., \& Tononi, G. (2007). Sleep homeostasis and cortical synchronization: I. Modeling the effects of synaptic strength on sleep slow waves. Sleep, 30, 1617-1630 Available at: Http://www.ncbi.nlm.nih.gov/pubmed/18246972 [Accessed January 3, 2018].

Esser, S. K., Hill, S., \& Tononi, G. (2009). Breakdown of effective connectivity during slow wave sleep: investigating the mechanism underlying a cortical gate using large-scale modeling. Journal of Neurophysiology, 102, 2096-2111 Available at: Http:// www.ncbi.nlm.nih.gov/pubmed/19657080 [Accessed January 3, 2018].

Fiebig, F., \& Lansner, A. (2014). Memory consolidation from seconds to weeks: A threestage neural network model with autonomous reinstatement dynamics. Frontiers in Computational Neuroscience, 8, 64 Available at: Http://www.ncbi.nlm.nih.gov/ pubmed/25071536 [Accessed October 6, 2016].

Fischer, S., Drosopoulos, S., Tsen, J., \& Born, J. (2006). Implicit learning - Explicit knowing: A role for sleep in memory system interaction. Journal of Cognitive Neuroscience, 18, 311-319 Available at: Http://www.ncbi.nlm.nih.gov/pubmed/ 16602193 [Accessed May 31, 2018].

Foster, D. J., \& Wilson, M. A. (2006). Reverse replay of behavioural sequences in hippocampal place cells during the awake state. Nature, 440, 680-683 Available at: https://vpn.upf.edu/ + CSCO

+ 0h756767633A2F2F6A6A6A2E616E676865722E70627A + +/nature/journal/ v440/n7084/full/nature04587.html [Accessed March 3, 2012].

Frank, M. G. (2012). Erasing synapses in sleep: Is it time to be SHY? Neural Plasticity, 2012, 1-15 Available at: Http://www.hindawi.com/journals/np/2012/264378/ [Accessed January 3, 2018].

Frank, M. G., Issa, N. P., \& Stryker, M. P. (2001). Sleep enhances plasticity in the developing visual cortex. Neuron, 30, 275-287 Available at: http://www.ncbi.nlm.nih.gov/pubmed/11343661 [Accessed January 12, 2018].

French, R. M., \& French (1999). Catastrophic forgetting in connectionist networks. Trends in Cognitive Sciences, 3, 128-135 Available at: http://www.ncbi.nlm.nih.gov/ pubmed/10322466 [Accessed January 17, 2018].

Frey, U., Krug, M., Reymann, K. G., \& Matthies, H. (1988). Anisomycin, an inhibitor of protein synthesis, blocks late phases of LTP phenomena in the hippocampal CA1 region in vitro. Brain Research, 452, 57-65 Available at: http://www.ncbi.nlm. nih.gov/pubmed/3401749 [Accessed January 4, 2018].

Gervasoni, D., Lin, S.-C., Ribeiro, S., Soares, E. S., Pantoja, J., \& Nicolelis, M. A. L. (2004). Global forebrain dynamics predict rat behavioral states and their transitions. Journal of Neuroscience, 24, 11137-11147 Available at: http://www.jneurosci.org/cgi/doi/ 10.1523/JNEUROSCI.3524-04.2004 [Accessed January 12, 2018].

Giuditta, A. (2014). Sleep memory processing: The sequential hypothesis. Frontiers in Systems Neuroscience, 8, 219 Available at: Http://www.ncbi.nlm.nih.gov/pubmed/ 25565985 [Accessed January 4, 2018].

Giuditta, A., Ambrosini, M. V., Montagnese, P., Mandile, P., Cotugno, M., Grassi Zucconi, G., ... Vescia, S. (1995). The sequential hypothesis of the function of sleep. Behavioural Brain Research, 69, 157-166 Available at: http://www.ncbi.nlm.nih.gov/ pubmed/7546307 [Accessed January 4, 2018].

González-Rueda, A., Pedrosa, V., Feord, R. C., Clopath, C., \& Paulsen, O. (2018). Activitydependent downscaling of subthreshold synaptic inputs during slow-wave-sleep-like activity in vivo. Neuron, 97, 1244-1252.e5 Available at: http://www.ncbi.nlm.nih.gov/pubmed/29503184 [Accessed May 31, 2018].

Grosmark, A. D., Mizuseki, K., Pastalkova, E., Diba, K., \& Buzsáki, G. (2012). REM sleep reorganizes hippocampal excitability. Neuron, 75, 1001-1007 Available at: http:// www.ncbi.nlm.nih.gov/pubmed/22998869 [Accessed January 24, 2018].

Grossberg, S. (1976). Adaptive pattern classification and universal recoding: I. Parallel development and coding of neural feature detectors. Biological Cybernetics, 23, 121-134 Available at: Http://www.ncbi.nlm.nih.gov/pubmed/974165 [Accessed August 7, 2014].

Hafting, T., Fyhn, M., Molden, S., Moser, M.-B., \& Moser, E. I. (2005). Microstructure of a spatial map in the entorhinal cortex. Nature, 436, 801-806.

Hager, A. M., \& Dringenberg, H. C. (2010). Assessment of different induction protocols to elicit long-term depression (LTD) in the rat visual cortex in vivo. Brain Research, 1318, 33-41 Available at: http://www.ncbi.nlm.nih.gov/pubmed/20051240 [Accessed January 4, 2018].

Hashambhoy, Y. L., Winslow, R. L., \& Greenstein, J. L. (2009). CaMKII-induced shift in modal gating explains L-type Ca2 + current facilitation: A modeling study. Biophysical Journal, 96, 1770-1785 Available at: Http://www.ncbi.nlm.nih.gov/ pubmed/19254537 [Accessed January 18, 2018].

Hashmi, A., Nere, A., \& Tononi, G. (2013). Sleep-dependent synaptic down-selection (II): Single-neuron level benefits for matching, selectivity, and specificity. Frontiers in Neurology, 4, 148 Available at: Http://www.ncbi.nlm.nih.gov/pubmed/24151486 [Accessed May 29, 2018].

Hasselmo, M. E. (2008). Temporally structured replay of neural activity in a model of entorhinal cortex, hippocampus and postsubiculum. European Journal of Neuroscience, 28, 1301-1315 Available at: http://www.ncbi.nlm.nih.gov/pubmed/18973557 [Accessed January 17, 2018].

Hasselmo, M. E. (2017). Avoiding catastrophic forgetting. Trends in Cognitive Sciences, 21, 407-408 Available at: http://www.ncbi.nlm.nih.gov/pubmed/28442279 [Accessed May 30, 2018].

Hattori, M. (2012). Avoiding catastrophic forgetting by a biologically inspired dual-network memory model. Berlin, Heidelberg: Springer pp. 392-400. Available at: http://link.springer.com/10.1007/978-3-642-34481-7_48 [Accessed May 30, 2018].

Havekes, R., Bruinenberg, V. M., Tudor, J. C., Ferri, S. L., Baumann, A., Meerlo, P., \& Abel, T. (2014). Transiently increasing cAMP levels selectively in hippocampal excitatory neurons during sleep deprivation prevents memory deficits caused by sleep loss. Journal of Neuroscience, 34, 15715-15721 Available at: http://www.ncbi.nlm.nih.gov/pubmed/25411499 [Accessed January 24, 2018].

Havekes, R., Park, A. J., Tolentino, R. E., Bruinenberg, V. M., Tudor, J. C., Lee, Y., ... Abel, T. (2016). Compartmentalized PDE4A5 signaling impairs hippocampal synaptic plasticity and long-term memory. Journal of Neuroscience, 36, 8936-8946 Available at: http://www.jneurosci.org/cgi/doi/10.1523/JNEUROSCI.0248-16.2016 [Accessed January 12, 2018].

Havekes, R., Park, A. J., Tudor, J. C., Luczak, V. G., Hansen, R. T., Ferri, S. L., ... Abel, T. (2016). Sleep deprivation causes memory deficits by negatively impacting neuronal connectivity in hippocampal area CA1. Elife, 5, e13424 Available at: https://elifesciences.org/articles/13424 [Accessed January 12, 2018].

Hebb, D. O. (1949). The organization of behavior: A neuropsychological theory. New York: Wiley.

Hengen, K. B., Torrado Pacheco, A., McGregor, J. N., Van Hooser, S. D., \& Turrigiano, G. G. (2016). Neuronal firing rate homeostasis is inhibited by sleep and promoted by wake. Cell, 165, 180-191 Available at: http://www.ncbi.nlm.nih.gov/pubmed/ 26997481 [Accessed January 12, 2018].

Hill, S., \& Tononi, G. (2005). Modeling sleep and wakefulness in the thalamocortical system. Journal of Neurophysiology, 93, 1671-1698 Available at: http:// www.ncbi.nlm.nih.gov/pubmed/15537811 [Accessed November 27, 2017].

Hinton, G. E., Dayan, P., Frey, B. J., \& Neal, R. M. (1995). The "wake-sleep" algorithm for unsupervised neural networks. Science, 268, 1158-1161 Available at: http:// www.ncbi.nlm.nih.gov/pubmed/7761831 [Accessed January 16, 2018].

Hobson, J. A., \& McCarley, R. W. (1971). Cortical unit activity in sleep and waking. Electroencephalography and Clinical Neurophysiology, 30, 97-112 Available at: http:// www.ncbi.nlm.nih.gov/pubmed/4100287 [Accessed January 12, 2018].

Hodgkin, A. L., \& Huxley, A. F. (1952). A quantitative description of membrane current and its application to conduction and excitation in nerve. Journal of Physiology, 117, 500-544 Available at: http://www.ncbi.nlm.nih.gov/pubmed/12991237 [Accessed January 3, 2018].

Holmes, W. R. (2000). Models of calmodulin trapping and CaM kinase II activation in a 
dendritic spine. Journal of Computational Neuroscience, 8, 65-85 Available at: http:// www.ncbi.nlm.nih.gov/pubmed/10798500 [Accessed January 18, 2018].

Hölscher, C., Anwyl, R., \& Rowan, M. J. (1997). Stimulation on the positive phase of hippocampal theta rhythm induces long-term potentiation that can Be depotentiated by stimulation on the negative phase in area CA1 in vivo. Journal of Neuroscience, 17, 6470-6477 Available at: http://www.ncbi.nlm.nih.gov/pubmed/9236254 [Accessed May 31, 2018].

Hubel, D. H., \& Wiesel, T. N. (1969). Anatomical demonstration of columns in the monkey striate cortex. Nature, 221, 747-750 Available at: http://www.ncbi.nlm.nih.gov/ pubmed/4974881 [Accessed January 12, 2018].

Hyman, J. M., Wyble, B. P., Goyal, V., Rossi, C. A., \& Hasselmo, M. E. (2003). Stimulation in hippocampal region CA1 in behaving rats yields long-term potentiation when delivered to the peak of theta and long-term depression when delivered to the trough. Journal of Neuroscience, 23, 11725-11731 Available at: http://www.ncbi.nlm.nih.gov/pubmed/14684874 [Accessed May 31, 2018].

Jadhav, S. P., Kemere, C., German, P. W., \& Frank, L. M. (2012). Awake hippocampal sharp-wave ripples support spatial memory. Science (80-), 336, 1454-1458 Available at: http://www.ncbi.nlm.nih.gov/pubmed/22555434 [Accessed May 30, 2018].

Jahnke, S., Timme, M., \& Memmesheimer, R.-M. (2015). A unified dynamic model for learning, replay, and sharp-wave/ripples. Journal of Neuroscience, 35, 16236-16258 Available at: http://www.ncbi.nlm.nih.gov/pubmed/26658873 [Accessed January 17, 2018].

Jarome, T. J., \& Helmstetter, F. J. (2014). Protein degradation and protein synthesis in long-term memory formation. Frontiers in Molecular Neuroscience, 7, 61 Available at: http://journal.frontiersin.org/article/10.3389/fnmol.2014.00061/abstract [Accessed January 16, 2018].

Jha, S. K., Brennan, F. X., Pawlyk, A. C., Ross, R. J., \& Morrison, A. R. (2005). REM sleep: A sensitive index of fear conditioning in rats. European Journal of Neuroscience, 21, 1077-1080 Available at: Http://www.ncbi.nlm.nih.gov/pubmed/15787712 [Accessed August 21, 2018].

Ji, D., \& Wilson, M. A. (2007). Coordinated memory replay in the visual cortex and hippocampus during sleep. Nature Neuroscience, 10, 100-107 Available at: http:// www.ncbi.nlm.nih.gov/pubmed/17173043 [Accessed May 31, 2018].

Johnson, A., \& Redish, A. D. (2005). Hippocampal replay contributes to within session learning in a temporal difference reinforcement learning model. Neural Networks, 18, 1163-1171 Available at: http://www.ncbi.nlm.nih.gov/pubmed/16198539 [Accessed July 12, 2012].

Kaczmarek, L., \& Chaudhuri, A. (1997). Sensory regulation of immediate-early gene expression in mammalian visual cortex: Implications for functional mapping and neural plasticity. Brain Research. Brain Research Reviews, 23, 237-256 Available at: Http:// www.ncbi.nlm.nih.gov/pubmed/9164673 [Accessed January 24, 2018].

Káli, S., \& Dayan, P. (2004). Off-line replay maintains declarative memories in a model of hippocampal-neocortical interactions. Nature Neuroscience, 7, 286-294 Available at: http://www.ncbi.nlm.nih.gov/pubmed/14983183 [Accessed January 15, 2018 ].

Kelly, A., Mullany, P. M., \& Lynch, M. A. (2000). Protein synthesis in entorhinal cortex and long-term potentiation in dentate gyrus. Hippocampus, 10, 431-437 Available at: http://www.ncbi.nlm.nih.gov/pubmed/10985282 [Accessed January 4, 2018].

Khodagholy, D., Gelinas, J. N., \& Buzsáki, G. (2017). Learning-enhanced coupling between ripple oscillations in association cortices and hippocampus. Science (80-), 358, 369-372 Available at: http://www.ncbi.nlm.nih.gov/pubmed/29051381 [Accessed January 24, 2018].

Kirkpatrick, J., Pascanu, R., Rabinowitz, N., Veness, J., Desjardins, G., Rusu, A. A., Hadsell, R. (2017). Overcoming catastrophic forgetting in neural networks. Proceedings of the National Academy of Sciences of the United States of America, 114, 3521-3526 Available at: http://www.ncbi.nlm.nih.gov/pubmed/28292907 [Accessed May 16, 2018].

Kohonen, T. (1982). Self-organized formation of topologically correct feature maps. Biological Cybernetics, 43, 59-69 Available at: http://link.springer.com/10.1007/ BF00337288 [Accessed June 9, 2016].

Komarov, M., Krishnan, G., Chauvette, S., Rulkov, N., Timofeev, I., \& Bazhenov, M. (2018). New class of reduced computationally efficient neuronal models for largescale simulations of brain dynamics. Journal of Computational Neuroscience, 44, 1-24 Available at: http://www.ncbi.nlm.nih.gov/pubmed/29230640 [Accessed May 31, 2018].

Kotaleski, J. H., \& Blackwell, K. T. (2010). Modelling the molecular mechanisms of synaptic plasticity using systems biology approaches. Nature Reviews Neuroscience, 11, 239-251 Available at: http://www.ncbi.nlm.nih.gov/pubmed/20300102 [Accessed January 18, 2018].

LeBlancq, M. J., McKinney, T. L., \& Dickson, C. T. (2016). ZIP it: neural silencing is an additional effect of the PKM-zeta inhibitor zeta-inhibitory peptide. Journal of Neuroscience, 36, 6193-6198 Available at: Http://www.ncbi.nlm.nih.gov/pubmed/ 27277798 [Accessed January 3, 2018].

Lee, A. K., \& Wilson, M. A. (2002). Memory of sequential experience in the hippocampus during slow wave sleep. Neuron, 36, 1183-1194 Available at: http:// www.ncbi.nlm.nih.gov/pubmed/12495631 [Accessed June 4, 2012].

Lerner, I. (2017a). Sleep is for the brain. Computational models of brain and behavior (pp. 245-256). Chichester, UK: John Wiley \& Sons, Ltd Available at: http://doi.wiley.com/10.1002/9781119159193.ch18 [Accessed May 30, 2018].

Lerner, I. (2017b). Unsupervised temporal learning during sleep supports insight. In Cognitive Computational Neuroscience (CCN) 2017. New York, New York, USA

Levy, W. B. (1996). A sequence predicting CA3 is a flexible associator that learns and uses context to solve hippocampal-like tasks. Hippocampus, 6, 579-590 Available at: http://www.ncbi.nlm.nih.gov/pubmed/9034847 [Accessed August 7, 2018].

Levy, W. B., Hocking, A. B., \& Wu, X. (2005). Interpreting hippocampal function as recoding and forecasting. Neural Networks, 18, 1242-1264 Available at: www.elsevier.com/locate/neunet [Accessed August 7, 2018].
Levy, W. B., \& Steward, O. (1983). Temporal contiguity requirements for long-term associative potentiation/depression in the hippocampus. Neuroscience, 8, 791-797 Available at: http://www.ncbi.nlm.nih.gov/pubmed/6306504 [Accessed May 31, 2018].

Lewis, P. A., \& Durrant, S. J. (2011). Overlapping memory replay during sleep builds cognitive schemata. Trends in Cognitive Sciences, 15, 343-351 Available at: http:// www.ncbi.nlm.nih.gov/pubmed/21764357 [Accessed May 29, 2018].

Li, W., Ma, L., Yang, G., \& Gan, W.-B. (2017). REM sleep selectively prunes and maintains new synapses in development and learning. Nature Neuroscience, 20, 427-437 Available at: http://www.ncbi.nlm.nih.gov/pubmed/28092659 [Accessed January $12,2018]$.

Lisman, J. E. (1985). A mechanism for memory storage insensitive to molecular turnover: A bistable autophosphorylating kinase. Proceedings of the National Academy of Sciences of the United States of America, 82, 3055-3057 Available at: Http://www.ncbi.nlm.nih.gov/pubmed/2986148 [Accessed January 3, 2018].

Lisman, J. (2017b). Glutamatergic synapses are structurally and biochemically complex because of multiple plasticity processes: Long-term potentiation, long-term depression, short-term potentiation and scaling. Philosophical Transactions of the Royal Society of London. Series B, Biological Sciences, 372, 20160260 Available at: Http:/ rstb.royalsocietypublishing.org/content/372/1715/20160260.long [Accessed April 18, 2017]

Lisman, J. (2017a). Criteria for identifying the molecular basis of the engram (CaMKII, PKMzeta). Molecular Brain, 10, 55 Available at: http://www.ncbi.nlm.nih.gov/ pubmed/29187215 [Accessed January 3, 2018].

Lisman, J. E., \& Jensen, O. (2013). The theta-gamma neural code. Neuron, 77, 1002-1016 Available at: doi: 10.1016/j.neuron.2013.03.007.

Lisman, J. E., \& Zhabotinsky, A. M. (2001). A model of synaptic memory: A CaMKII/PP1 switch that potentiates transmission by organizing an AMPA receptor anchoring assembly. Neuron, 31, 191-201 Available at: Http://www.ncbi.nlm.nih.gov/pubmed/ 11502252 [Accessed January 18, 2018].

Liu, K. K. L., Hagan, M. F., \& Lisman, J. E. (2017). Gradation (approx. 10 size states) of synaptic strength by quantal addition of structural modules. Philosophical transactions of the Royal Society of London. Series B, Biological Sciences, 372, 20160328 Available at: http://www.ncbi.nlm.nih.gov/pubmed/28093559 [Accessed January 3, 2018].

Lopez, J., Roffwarg, H. P., Dreher, A., Bissette, G., Karolewicz, B., \& Shaffery, J. P. (2008). Rapid eye movement sleep deprivation decreases long-term potentiation stability and affects some glutamatergic signaling proteins during hippocampal development. Neuroscience, 153, 44-53 Available at: http://www.ncbi.nlm.nih.gov/pubmed/ 18359575 [Accessed January 12, 2018].

Lu, L., Leutgeb, J. K., Tsao, A., Henriksen, E. J., Leutgeb, S., Barnes, C. A., ... Moser, E. I. (2013). Impaired hippocampal rate coding after lesions of the lateral entorhinal cortex. Nature Neuroscience, 16, 1085-1093 Available at: doi: 10.1038/nn.3462 [Accessed July 14, 2013].

Lubenov, E. V., \& Siapas, A. G. (2008). Decoupling through synchrony in neuronal circuits with propagation delays. Neuron, 58, 118-131 Available at: http://www.ncbi.nlm.nih.gov/pubmed/18400168 [Accessed May 31, 2018].

Lučić, V., Greif, G. J., \& Kennedy, M. B. (2008). Detailed state model of CaMKII activation and autophosphorylation. European Biophysics Journal, 38, 83-98 Available at: http:// www.ncbi.nlm.nih.gov/pubmed/18769913 [Accessed January 18, 2018].

Ma, Y., Shi, W., Peng, C.-K., \& Yang, A. C. (2018). Nonlinear dynamical analysis of sleep electroencephalography using fractal and entropy approaches. Sleep Medicine Reviews, 37, 85-93 Available at: http://www.ncbi.nlm.nih.gov/pubmed/28392169 [Accessed January 5, 2018].

Magleby, K. L., \& Zengel, J. E. (1976). Augmentation: A process that acts to increase transmitter release at the frog neuromuscular junction. Journal of Physiology, 257, 449-470 Available at: Http://www.ncbi.nlm.nih.gov/pubmed/820854 [Accessed January 3, 2018].

Markram, H., Lübke, J., Frotscher, M., \& Sakmann, B. (1997). Regulation of synaptic efficacy by coincidence of postsynaptic APs and EPSPs. Science, 275, 213-215 Available at: http://www.ncbi.nlm.nih.gov/pubmed/8985014 [Accessed January 4, 2018].

Markram, H., Muller, E., Ramaswamy, S., Reimann, M. W., Abdellah, M., Sanchez, C. A., ... Schürmannuado, F. (2015). Reconstruction and simulation of neocortical microcircuitry. Cell, 163, 456-492 Available at: http://www.ncbi.nlm.nih.gov/pubmed/ 26451489 [Accessed January 18, 2018].

Marr, D. (1971). Simple memory: A theory for archicortex. Philosophical Transactions of the Royal Society of London. Series B, Biological Sciences, 262, 23-81 Available at: Http://rstb.royalsocietypublishing.org/cgi/content/abstract/262/841/23.

Marshall, L., \& Born, J. (2007). The contribution of sleep to hippocampus-dependent memory consolidation. Trends in Cognitive Sciences, 11, 442-450 Available at: http:// www.ncbi.nlm.nih.gov/pubmed/17905642 [Accessed January 3, 2018].

Marshall, L., Helgadóttir, H., Mölle, M., \& Born, J. (2006). Boosting slow oscillations during sleep potentiates memory. Nature, 444, 610-613 Available at: http:// www.ncbi.nlm.nih.gov/pubmed/17086200 [Accessed May 31, 2018].

Matsuzaki, M., Honkura, N., Ellis-Davies, G. C. R., \& Kasai, H. (2004). Structural basis of long-term potentiation in single dendritic spines. Nature, 429, 761-766 Available at: http://www.ncbi.nlm.nih.gov/pubmed/15190253 [Accessed January 3, 2018].

Mayford, M., Bach, M. E., Huang, Y. Y., Wang, L., Hawkins, R. D., \& Kandel, E. R. (1996) Control of memory formation through regulated expression of a CaMKII transgene. Science, 274, 1678-1683 Available at: http://www.ncbi.nlm.nih.gov/pubmed/ 8939850 [Accessed May 31, 2018].

McClelland, J. L., McNaughton, B. L., \& O'Reilly, R. C. (1995). Why there are complementary learning systems in the hippocampus and neocortex: Insights from the successes and failures of connectionist models of learning and memory. Psychological Review, 102, 419-457 Available at: Http://www.ncbi.nlm.nih.gov/pubmed/7624455 [Accessed January 15, 2018]. 
McNaughton, B. L., Battaglia, F. P., Jensen, O., Moser, E. I., \& Moser, M.-B. (2006). Path integration and the neural basis of the "cognitive map". Nature Reviews Neuroscience, 7, 663-678 Available at: doi: 10.1038/nrn1932.

Messaoudi, E., Kanhema, T., Soule, J., Tiron, A., Dagyte, G., da Silva, B., \& Bramham, C. R. (2007). Sustained Arc/Arg3.1 synthesis controls long-term potentiation consolidation through regulation of local actin polymerization in the dentate gyrus in vivo. Journal of Neuroscience, 27, 10445-10455 Available at: http:// www.ncbi.nlm.nih.gov/pubmed/17898216 [Accessed January 24, 2018].

Meyer, D., Bonhoeffer, T., \& Scheuss, V. (2014). Balance and stability of synaptic struc tures during synaptic plasticity. Neuron, 82, 430-443 Available at: http:// www.ncbi.nlm.nih.gov/pubmed/24742464 [Accessed January 4, 2018].

Minai, A. A., \& Levy, W. B. (1993). Sequence learning in a single trial. In INNS world congress of neural networks II. Available at: http://citeseerx.ist.psu.edu/viewdoc/ download?doi $=10 \cdot 1 \cdot 1 \cdot 73.7092 \&$ rep $=$ rep1\&type $=$ pdf $[$ Accessed August 7, 2018]

Mishkin, M. (1982). A memory system in the monkey. Philosophical Transactions of the Royal Society of London. Series B, Biological Sciences, 298, 83-95 Available at: http:// www.ncbi.nlm.nih.gov/pubmed/6125978 [Accessed January 15, 2018].

Miyawaki, H., \& Diba, K. (2016). Regulation of hippocampal firing by network oscillations during sleep. Current Biology, 26, 893-902 Available at: http:// www.ncbi.nlm.nih.gov/pubmed/26972321 [Accessed May 31, 2018].

Molter, C., Sato, N., \& Yamaguchi, Y. (2007). Reactivation of behavioral activity during sharp waves: A computational model for two stage hippocampal dynamics. Hippocampus, 17, 201-209 Available at: Http://www.ncbi.nlm.nih.gov/pubmed/ 17294461 [Accessed January 17, 2018].

Morris, R. G. M. (2003). Long-term potentiation and memory. Philosophical Transactions of the Royal Society of London. Series B, Biological sciences, 358, 643-647 Available at: http://rstb.royalsocietypublishing.org/cgi/doi/10.1098/rstb.2002.1230[Accessed January 3, 2018].

Mozzachiodi, R., \& Byrne, J. H. (2010). More than synaptic plasticity: Role of nonsynaptic plasticity in learning and memory. Trends in Neurosciences, 33, 17-26 Available at: Http://www.ncbi.nlm.nih.gov/pubmed/19889466 [Accessed January 4, 2018].

Nabavi, S., Fox, R., Proulx, C. D., Lin, J. Y., Tsien, R. Y., \& Malinow, R. (2014). Engineering a memory with LTD and LTP. Nature, 511, 348-352 Available at: http:// www.ncbi.nlm.nih.gov/pubmed/24896183 [Accessed January 3, 2018].

Nádasdy, Z., Hirase, H., Czurkó, A., Csicsvari, J., \& Buzsáki, G. (1999). Replay and time compression of recurring spike sequences in the hippocampus. Journal of Neuroscience, 19, 9497-9507 Available at: http://www.ncbi.nlm.nih.gov/pubmed/ 10531452 [Accessed January 24, 2018].

Neher, E., \& Sakmann, B. (1976). Single-channel currents recorded from membrane of denervated frog muscle fibres. Nature, 260, 799-802 Available at: http://www.nature.com/doifinder/10.1038/260799a0 [Accessed January 3, 2018].

Nere, A., Hashmi, A., Cirelli, C., \& Tononi, G. (2013). Sleep-dependent synaptic downselection (I): Modeling the benefits of sleep on memory consolidation and integration. Frontiers in Neurology, 4, 143 Available at: Http://www.ncbi.nlm.nih.gov/pubmed 24137153 [Accessed January 3, 2018].

Nere, A., Olcese, U., Balduzzi, D., \& Tononi, G. (2012). A Neuromorphic architecture for object recognition and motion anticipation using burst-STDP Wennekers T, ed. PLoS ONE, 7, e36958 Available at: http://www.ncbi.nlm.nih.gov/pubmed/22615855 [Accessed January 3, 2018].

Nicoll, R. A., \& Malenka, R. C. (1999). Expression mechanisms underlying NMDA receptor-dependent long-term potentiation. Annals of the New York Academy of Sciences, 868, 515-525 Available at: http://www.ncbi.nlm.nih.gov/pubmed/10414328 [Accessed January 5, 2018].

Noda, H., Manohar, S., \& Adey, W. R. (1969). Spontaneous activity of cat hippocampal neurons in sleep and wakefulness. Experimental Neurology, 24, 217-231 Available at: http://www.ncbi.nlm.nih.gov/pubmed/4306533 [Accessed January 12, 2018].

Norman, K. A., Newman, E. L., \& Perotte, A. J. (2005). Methods for reducing interference in the Complementary Learning Systems model: Oscillating inhibition and autonomous memory rehearsal. Neural Networks, 18, 1212-1228 Available at: Http:// www.ncbi.nlm.nih.gov/pubmed/16260116 [Accessed January 17, 2018].

O'Keefe, J., \& Dostrovsky, J. (1971). The hippocampus as a spatial map. Preliminary evidence from unit activity in the freely-moving rat. Brain Research, 34, 171-175 Available at: http://www.ncbi.nlm.nih.gov/pubmed/5124915.

O'Keefe, J., \& Nadel, L. (1978). The hippocampus as a cognitive map. Oxford: Oxford University Press.

O’Neill, J., Pleydell-Bouverie, B., Dupret, D., \& Csicsvari, J. (2010). Play it again: Reactivation of waking experience and memory. Trends in Neurosciences, 33, 220-229 Available at: Http://www.ncbi.nlm.nih.gov/pubmed/20207025 [Accessed May 31, 2018].

Olcese, U., Esser, S. K., \& Tononi, G. (2010). Sleep and synaptic renormalization: A computational study. Journal of Neurophysiology, 104, 3476-3493 Available at: Http://www.ncbi.nlm.nih.gov/pubmed/20926617 [Accessed January 3, 2018].

Pavlides, C., Greenstein, Y. J., Grudman, M., \& Winson, J. (1988). Long-term potentiation in the dentate gyrus is induced preferentially on the positive phase of theta-rhythm. Brain Research, 439, 383-387 Available at: http://www.ncbi.nlm.nih.gov/pubmed/ 3359196 [Accessed May 31, 2018].

Pavlides, C., \& Winson, J. (1989). Influences of hippocampal place cell firing in the awake state on the activity of these cells during subsequent sleep episodes. Journal of Neuroscience, 9, 2907-2918 Available at: http://www.ncbi.nlm.nih.gov/pubmed/ 2769370 [Accessed January 3, 2018].

Penke, Z., Chagneau, C., \& Laroche, S. (2011). Contribution of Egr1/zif268 to activitydependent Arc/Arg3.1 transcription in the dentate gyrus and area CA1 of the hippocampus. Frontiers in Behavioral Neuroscience, 5, 48 Available at: http://journal-frontiersin.org/article/10.3389/fnbeh.2011.00048/abstract [Accessed January 4, 2018].

Peyrache, A., Battaglia, F. P., \& Destexhe, A. (2011). Inhibition recruitment in prefrontal cortex during sleep spindles and gating of hippocampal inputs. Proceedings of the National Academy of Sciences of the United States of America, 108, 17207-17212 Available at: http://www.ncbi.nlm.nih.gov/pubmed/21949372 [Accessed May 30, 2018].

Peyrache, A., Khamassi, M., Benchenane, K., Wiener, S. I., \& Battaglia, F. P. (2009). Replay of rule-learning related neural patterns in the prefrontal cortex during sleep. Nature Neuroscience, 12, 919-926 Available at: http://www.ncbi.nlm.nih.gov/ pubmed/19483687 [Accessed January 24, 2018].

Poe, G. R., Walsh, C. M., \& Bjorness, T. E. (2010). Cognitive neuroscience of sleep. In Progress in brain research (pp 1-19). Available at: http://www.ncbi.nlm.nih.gov/ pubmed/21075230 [Accessed January 12, 2018].

Pompeiano, M., Cirelli, C., Arrighi, P., \& Tononi, G. (1995). c-Fos expression during wakefulness and sleep. Clinical Neurophysiology, 25, 329-341 Available at: http:// www.ncbi.nlm.nih.gov/pubmed/8904195 [Accessed January 12, 2018].

Pompeiano, M., Cirelli, C., Ronca-Testoni, S., \& Tononi, G. (1997). NGFI-A expression in the rat brain after sleep deprivation. Brain Research. Molecular Brain Research, 46, 143-153 Available at: http://www.ncbi.nlm.nih.gov/pubmed/9191088 [Accessed January 12, 2018].

Pompeiano, M., Cirelli, C., \& Tononi, G. (1992). Effects of sleep deprivation on fos-like immunoreactivity in the rat brain. Archives Italiennes de Biologie, 130, 325-335 Available at: http://www.ncbi.nlm.nih.gov/pubmed/1489251 [Accessed January 12, 2018].

Pompeiano, Cirelli, \& Tononi (1994). Immediate-early genes in spontaneous wakefulness and sleep: Expression of c-fos and NGFI-A mRNA and protein. Journal of Sleep Research, 3, 80-96 Available at: Http://www.ncbi.nlm.nih.gov/pubmed/10607112 [Accessed January 12, 2018].

Puentes-Mestril, C., \& Aton, S. J. (2017). Linking network activity to synaptic plasticity during sleep: Hypotheses and recent data. Frontiers in Neural Circuits, 11, 61 Available at: Http://www.ncbi.nlm.nih.gov/pubmed/28932187 [Accessed January 3, 2018].

Rasch, B., \& Born, J. (2013). About sleep's role in memory. Physiological Reviews, 93, 681-766 Available at: http://www.ncbi.nlm.nih.gov/pubmed/23589831 [Accessed January 3, 2018].

Ravassard, P., Hamieh, A. M., Joseph, M. A., Fraize, N., Libourel, P.-A., Lebarillier, L., Salin, P.-A. (2016). REM sleep-dependent bidirectional regulation of hippocampalbased emotional memory and LTP. Cerebral Cortex, 26, 1488-1500 Available at: http://www.ncbi.nlm.nih.gov/pubmed/25585510 [Accessed January 24, 2018]

Ravassard, P., Pachoud, B., Comte, J.-C., Mejia-Perez, C, Scoté-Blachon, C., Gay, N. .... Salin, P. A. (2009). Paradoxical (REM) sleep deprivation causes a large and rapidly reversible decrease in long-term potentiation, synaptic transmission, glutamate receptor protein levels, and ERK/MAPK activation in the dorsal hippocampus. Sleep, 32, 227-240 Available at: http://www.ncbi.nlm.nih.gov/pubmed/19238810 [Accessed January 12, 2018].

Rennó-Costa, C., Lisman, J. E., \& Verschure, P. F. M. J. (2010). The mechanism of rate remapping in the dentate gyrus. Neuron, 68, 1051-1058 Available at: http:// www.cell.com/neuron/fulltext/S0896-6273(10)00940-2 [Accessed December 22, 2010].

Rennó-Costa, C., Lisman, J. E., \& Verschure, P. F. M. J. (2014). A signature of attractor dynamics in the CA3 region of the hippocampus Sporns O, ed. PLoS Computational Biology, 10, e1003641 Available at: http://www.pubmedcentral.nih.gov/articler ender.fcgi artid $=4031055 \&$ tool $=$ pmcentrez\&rendertype $=$ abstract [Accessed May 23, 2014].

Rennó-Costa, C., \& Tort, A. B. L. L. (2017). Place and grid cells in a loop: Implications for memory function and spatial coding. Journal of Neuroscience, 37, 3490-3516 Available at: Http://www.jneurosci.org/lookup/doi/10.1523/JNEUROSCI.349016.2017 [Accessed September 5, 2018].

Ribeiro, S. (2012). Sleep and. Pflügers Archiv European Journal of Physiology, 463, 111-120 Available at: http://www.ncbi.nlm.nih.gov/pubmed/21947578 [Accessed January 12, 2018]

Riedner, B. A., Vyazovskiy, V. V., Huber, R., Massimini, M., Esser, S., Murphy, M., \& Tononi, G. (2007). Sleep homeostasis and cortical synchronization: III. A high-density EEG study of sleep slow waves in humans. Sleep, 30(12), 1643-1657 https:// www.ncbi.nlm.nih.gov/pubmed/18246974.

Ribeiro, S., Gervasoni, D., Soares, E. S., Zhou, Y., Lin, S.-C., Pantoja, J., Lavine, M., \& Nicolelis, M. A. L. (2004). Long-lasting novelty-induced neuronal reverberation during slow-wave sleep in multiple forebrain areas. Wolfram Schultz, ed. PLoS Biology, 2, E24 Available at: http://journals.plos.org/plosbiology/article?id=10.1371/journal.pbio.0020024 [Accessed January 18, 2016].

Ribeiro, S., Goyal, V., Mello, C. V., \& Pavlides, C. (1999). Brain gene expression during REM sleep depends on prior waking experience. Learning \& Memory, 6, 500-508 Available at: http://www.ncbi.nlm.nih.gov/pubmed/10541470 [Accessed January $12,2018]$.

Ribeiro, S., Mello, C. V., Velho, T., Gardner, T. J., Jarvis, E. D., \& Pavlides, C. (2002). Induction of hippocampal long-term potentiation during waking leads to increased extrahippocampal zif-268 expression during ensuing rapid-eye-movement sleep. Journal of Neuroscience, 22, 10914-10923 Available at: http://www.jneurosci.org/ content/22/24/10914.short [Accessed January 18, 2016].

Ribeiro, S., \& Nicolelis, M. A. L. (2004). Reverberation, storage, and postsynaptic propagation of memories during sleep. Learning \& Memory, 11, 686-696 Available at: http://www.ncbi.nlm.nih.gov/pubmed/15576886 [Accessed October 6, 2016].

Ribeiro, S., Shi, X., Engelhard, M., Zhou, Y., Zhang, H., Gervasoni, D., ... Nicolelis, M. A. L. (2007). Novel experience induces persistent sleep-dependent plasticity in the cortex but not in the hippocampus. Frontiers in Neuroscience, 1, 43-55 Available at: http:// journal.frontiersin.org/article/10.3389/neuro.01.1.1.003.2007/abstract [Accessed January 12, 2018].

Rothschild, G., Eban, E., \& Frank, L. M. (2017). A cortical-hippocampal-cortical loop of information processing during memory consolidation. Nature Neuroscience, 20 , 
251-259 Available at: http://www.ncbi.nlm.nih.gov/pubmed/27941790 [Accessed May 30, 2018].

Rubino, D., Robbins, K. A., \& Hatsopoulos, N. G. (2006). Propagating waves mediate information transfer in the motor cortex. Nature Neuroscience, 9, 1549-1557 Available at: http://www.nature.com/articles/nn1802 [Accessed August 21, 2018].

Rudoy, J. D., Voss, J. L., Westerberg, C. E., \& Paller, K. A. (2009). Strengthening individual memories by reactivating them during sleep. Science (80-), 326, 1079-1079 Available at: http://www.ncbi.nlm.nih.gov/pubmed/19965421 [Accessed May 31, 2018].

Sacktor, T. (2012). Memory maintenance by PKM —An evolutionary perspective. Molecular Brain, 5, 31 Available at: http://www.ncbi.nlm.nih.gov/pubmed/ 22986281 [Accessed January 3, 2018].

Sanders, H., Rennó-Costa, C., Idiart, M. A. P., \& Lisman, J. E. (2015). Grid cells and place cells: An integrated view of their navigational/memory function. Trends in Neurosciences, 763-775 Available at: http://www.ncbi.nlm.nih.gov/pubmed/ 26616686 [Accessed November 28, 2015] (in press).

Sanhueza, M., \& Lisman, J. (2013). The CaMKII/NMDAR complex as a molecular memory. Molecular Brain, 6, 10 Available at: http://www.ncbi.nlm.nih.gov/pubmed/ 23410178 [Accessed January 3, 2018].

Seibt, J., Dumoulin, M. C., Aton, S. J., Coleman, T., Watson, A., Naidoo, N., \& Frank, M. G. (2012). Protein synthesis during sleep consolidates cortical plasticity in vivo. Current Biology, 22, 676-682 Available at: http://www.ncbi.nlm.nih.gov/pubmed/22386312 [Accessed January 12, 2018].

Sejnowski, T. J., \& Destexhe, A. (2000). Why do we sleep? Brain Research, 886, 208-223 Available at: http://www.ncbi.nlm.nih.gov/pubmed/11119697 [Accessed January 3, 2018].

Shaffery, J. P., Lopez, J., Bissette, G., \& Roffwarg, H. P. (2006). Rapid eye movement sleep deprivation revives a form of developmentally regulated synaptic plasticity in the visual cortex of post-critical period rats. Neuroscience Letters, 391, 96-101 Available at: http://www.ncbi.nlm.nih.gov/pubmed/16154270 [Accessed January 12, 2018 ].

Shaffery, J. P., Lopez, J., \& Roffwarg, H. P. (2012). Brain-derived neurotrophic factor (BDNF) reverses the effects of rapid eye movement sleep deprivation (REMSD) on developmentally regulated, long-term potentiation (LTP) in visual cortex slices. Neuroscience Letters, 513, 84-88 Available at: http://www.ncbi.nlm.nih.gov/ pubmed/22361363 [Accessed January 12, 2018].

Shen, B., \& McNaughton, B. L. (1996). Modeling the spontaneous reactivation of experience-specific hippocampal cell assembles during sleep. Hippocampus, 6, 685-692 Available at: http://www.ncbi.nlm.nih.gov/pubmed/9034855 [Accessed January 15, 2018].

Shepherd, J. D., Rumbaugh, G., Wu, J., Chowdhury, S., Plath, N., Kuhl, D., ... Worley, P. F. (2006). Arc/Arg3.1 mediates homeostatic synaptic scaling of AMPA receptors. Neuron, 52, 475-484 Available at: http://www.ncbi.nlm.nih.gov/pubmed/17088213 [Accessed January 24, 2018].

Sheroziya, M., \& Timofeev, I. (2014). Global intracellular slow-wave dynamics of the thalamocortical system. Journal of Neuroscience, 34, 8875-8893 Available at: http:// www.ncbi.nlm.nih.gov/pubmed/24966387 [Accessed May 31, 2018].

Shimizu, E., Tang, Y. P., Rampon, C., \& Tsien, J. Z. (2000). NMDA receptor-dependent synaptic reinforcement as a crucial process for memory consolidation. Science, 290, 1170-1174 Available at: http://www.ncbi.nlm.nih.gov/pubmed/11073458 [Accessed January 15, 2018].

Shou, W., Bergstrom, C. T., Chakraborty, A. K., \& Skinner, F. K. (2015). Theory, models and biology. Elife, 4, e07158 Available at: http://www.ncbi.nlm.nih.gov/pubmed/ 26173204 [Accessed January 5, 2018].

Silva, A. J., Stevens, C. F., Tonegawa, S., \& Wang, Y. (1992). Deficient hippocampal longterm potentiation in alpha-calcium-calmodulin kinase II mutant mice. Science, 257, 201-206 Available at: http://www.ncbi.nlm.nih.gov/pubmed/1378648 [Accessed January 12, 2018].

Sjöström, P. J., Turrigiano, G. G., \& Nelson, S. B. (2001). Rate, timing, and cooperativity jointly determine cortical synaptic plasticity. Neuron, 32, 1149-1164 Available at: http://www.ncbi.nlm.nih.gov/pubmed/11754844 [Accessed January 4, 2018].

Skaggs, W. E., \& McNaughton, B. L. (1996). Theta phase precession in hippocampal neurinak populations and the compression of. Hippocampus, 6, 149-172.

Squire, L. R., Stark, C. E. L. L., \& Clark, R. E. (2004). The medial temporal lobe. Annual Review of Neuroscience, 27, 279-306 Available at: http://www.ncbi.nlm.nih.gov/ pubmed/15217334 [Accessed July 9, 2014].

Steriade, M., Timofeev, I., \& Grenier, F. (2001). Natural waking and sleep states: A view from inside neocortical neurons. Journal of Neurophysiology, 85, 1969-1985 Available at: Http://www.ncbi.nlm.nih.gov/pubmed/11353014 [Accessed January 17, 2018].

Stickgold, R., \& Walker, M. P. (2013). Sleep-dependent memory triage: Evolving generalization through selective processing. Nature Neuroscience, 16, 139-145 Available at: Http://www.ncbi.nlm.nih.gov/pubmed/23354387 [Accessed May 31, 2018].

Stickgold, R., Whidbee, D., Schirmer, B., Patel, V., \& Hobson, J. A. (2000). Visual discrimination task improvement: A multi-step process occurring during sleep. Journal of Cognitive Neuroscience, 12, 246-254 Available at: Http://www.ncbi.nlm.nih.gov/ pubmed/10771409 [Accessed May 30, 2018].

Sullivan, T. J., \& de Sa, V. R. (2006). Homeostatic synaptic scaling in self-organizing maps. Neural Networks, 19, 734-743 Available at: http://www.ncbi.nlm.nih.gov/ pubmed/16782305 [Accessed November 27, 2017].

Sullivan, T. J., \& de Sa, V. R. (2008). Sleeping our way to weight normalization and stable learning. Neural Computation, 20, 3111-3130 Available at: http://www.mitpressjournals.org/doi/10.1162/neco.2008.04-07-502 [Accessed January 3, 2018].

Takeuchi, T., Duszkiewicz, A. J., \& Morris, R. G. M. (2014). The synaptic plasticity and memory hypothesis: Encoding, storage and persistence. Philosophical Transactions of the Royal Society of London. Series B, Biological Sciences, 369, 20130288 Available at: Http://www.ncbi.nlm.nih.gov/pubmed/24298167 [Accessed January 3, 2018].

Tatsuno, M., Lipa, P., \& McNaughton, B. L. (2006). Methodological considerations on the use of template matching to study long-lasting memory trace replay. Journal of Neuroscience, 26, 10727-10742 Available at: http://www.ncbi.nlm.nih.gov/pubmed/ 17050712 [Accessed May 31, 2018].

Teyler, T. J., \& DiScenna, P. (1986). The hippocampal memory indexing theory. Behavioral Neuroscience, 100, 147-154 Available at: http://www.ncbi.nlm.nih.gov/ pubmed/3008780 [Accessed July 27, 2012].

Tolman, E. C. (1948). Cognitive maps in rats and men. Psychological Review, 55, 189-208.

Tononi, G., \& Cirelli, C. (2003). Sleep and synaptic homeostasis: A hypothesis. Brain Research Bulletin, 62, 143-150 Available at: Http://www.ncbi.nlm.nih.gov/pubmed/ 14638388 [Accessed January 3, 2018].

Tononi, G., \& Cirelli, C. (2014). Sleep and the price of plasticity: From synaptic and cellular homeostasis to memory consolidation and integration. Neuron, 81, 12-34 Available at: Http://www.ncbi.nlm.nih.gov/pubmed/24411729 [Accessed May 18, 2017].

Tsodyks, M. V., \& Markram, H. (1997). The neural code between neocortical pyramidal neurons depends on neurotransmitter release probability. Proceedings of the National Academy of Sciences of the United States of America, 94, 719-723 Available at: http:// www.ncbi.nlm.nih.gov/pubmed/9012851 [Accessed August 21, 2018].

Tsokas, P., Hsieh, C., Yao, Y., Lesburguères, E., Wallace, E. J. C., Tcherepanov, A., ... Sacktor, T. C. (2016). Compensation for PKM $\zeta$ in long-term potentiation and spatial long-term memory in mutant mice. Elife, 5 Available at: http://www.ncbi.nlm.nih.gov/pubmed/27187150 [Accessed January 3, 2018].

Turrigiano, G. G. (2017). The dialectic of Hebb and homeostasis. Philosophical Transactions of the Royal Society of London. Series B, Biological Sciences, 372, 20160258 Available at: http://www.ncbi.nlm.nih.gov/pubmed/28093556 [Accessed January 4, 2018].

Turrigiano, G. G., Leslie, K. R., Desai, N. S., Rutherford, L. C., \& Nelson, S. B. (1998). Activity-dependent scaling of quantal amplitude in neocortical neurons. Nature, 391, 892-896 Available at: http://www.ncbi.nlm.nih.gov/pubmed/9495341 [Accessed January 12, 2018].

Turrigiano, G. G., \& Nelson, S. B. (2004). Homeostatic plasticity in the developing nervous system. Nature Reviews Neuroscience, 5, 97-107 Available at: http:// www.ncbi.nlm.nih.gov/pubmed/14735113 [Accessed January 12, 2018].

Ulloor, J., \& Datta, S. (2005). Spatio-temporal activation of cyclic AMP response elementbinding protein, activity-regulated cytoskeletal-associated protein and brain-derived nerve growth factor: A mechanism for pontine-wave generator activation-dependent two-way active-avoidance memory processing in the rat. Journal of Neurochemistry, 95, 418-428 Available at: Http://doi.wiley.com/10.1111/j.1471-4159.2005.03378.x [Accessed January 12, 2018].

Valton, V., Romaniuk, L., Douglas Steele, J., Lawrie, S., \& Seriès, P. (2017). Comprehensive review: Computational modelling of schizophrenia. Neuroscience \& Biobehavioral Reviews, 83, 631-646 Available at: Http://www.ncbi.nlm.nih.gov/ pubmed/28867653 [Accessed January 5, 2018].

van de Ven, G. M., Trouche, S., McNamara, C. G., Allen, K., \& Dupret, D. (2016). Hippocampal offline reactivation consolidates recently formed cell assembly patterns during sharp wave-ripples. Neuron, 92, 968-974 Available at: http://linkinghub.elsevier.com/retrieve/pii/S0896627316307218 [Accessed January 12, 2018].

van Rossum, M. C. W., Bi, G. Q., \& Turrigiano, G. G. (2000). Stable Hebbian learning from spike timing-dependent plasticity. Journal of Neuroscience, 20, 8812-8821 Available at: http://www.jneurosci.org/content/20/23/8812.abstract [Accessed May 2, 2014].

Vecsey, C. G., Baillie, G. S., Jaganath, D., Havekes, R., Daniels, A., Wimmer, M., ... Abel, T. (2009). Sleep deprivation impairs cAMP signalling in the hippocampus. Nature, 461, 1122-1125 Available at: http://www.nature.com/articles/nature08488 [Accessed January 12, 2018].

Vorster, A. P., \& Born, J. (2015). Sleep and memory in mammals, birds and invertebrates. Neuroscience \& Biobehavioral Reviews, 50, 103-119 Available at: http:// www.ncbi.nlm.nih.gov/pubmed/25305058 [Accessed January 3, 2018].

Vyazovskiy, V. V., Riedner, B. A., Cirelli, C., \& Tononi, G. (2007). Sleep homeostasis and cortical synchronization: II. A local field potential study of sleep slow waves in the rat. Sleep, 30(12), 1631-1642 https://www.ncbi.nlm.nih.gov/pubmed/18246973.

Vyazovskiy, V. V., Cirelli, C., Tononi, G., \& Tobler, I. (2008). Cortical metabolic rates as measured by 2-deoxyglucose-uptake are increased after waking and decreased after sleep in mice. Brain Research Bulletin, 75, 591-597 Available at: http://linkinghub.elsevier.com/retrieve/pii/S0361923007003243 [Accessed January 12, 2018].

Vyazovskiy, V. V., Olcese, U., Lazimy, Y. M., Faraguna, U., Esser, S. K., Williams, J. C., .. Tononi, G. (2009). Cortical firing and sleep homeostasis. Neuron, 63, 865-878 Available at: http://www.ncbi.nlm.nih.gov/pubmed/19778514 [Accessed May 31, 2018].

Wagner, U., Gais, S., Haider, H., Verleger, R., \& Born, J. (2004). Sleep inspires insight. Nature, 427, 352-355 Available at: http://www.ncbi.nlm.nih.gov/pubmed/ 14737168 [Accessed May 31, 2018].

Walker, M. P., \& Stickgold, R. (2004). Sleep-dependent learning and memory consolidation. Neuron, 44, 121-133 Available at: https://www.sciencedirect.com/science/article/pii/S0896627304005409 [Accessed January 4, 2018].

Walker, M. P., \& Stickgold, R. (2010). Overnight alchemy: sleep-dependent memory evolution. Nature Reviews Neuroscience, 11, 218 author reply 218. Available at: http://www.ncbi.nlm.nih.gov/pubmed/20168316 [Accessed May 29, 2018].

Waung, M. W., Pfeiffer, B. E., Nosyreva, E. D., Ronesi, J. A., \& Huber, K. M. (2008). Rapid translation of Arc/Arg3.1 selectively mediates mGluR-dependent LTD through persistent increases in AMPAR endocytosis rate. Neuron, 59, 84-97 Available at: http:// www.ncbi.nlm.nih.gov/pubmed/18614031 [Accessed January 24, 2018].

Wei, Y., Krishnan, G. P., \& Bazhenov, M. (2016). Synaptic mechanisms of memory consolidation during sleep slow oscillations. Journal of Neuroscience, 36, 4231-4247 Available at: http://www.jneurosci.org/content/jneuro/36/15/4231.full.pdf [Accessed October 6, 2016].

Whitlock, J. R., Heynen, A. J., Shuler, M. G., \& Bear, M. F. (2006). Learning induces long- 
term potentiation in the hippocampus. Science (80-), 313, 1093-1097 Available at: http://www.ncbi.nlm.nih.gov/pubmed/16931756 [Accessed January 3, 2018].

Wickelgren, W. A. (1979). Chunking and consolidation: A theoretical synthesis of semantic networks, configuring in conditioning, S-R versus congenitive learning, normal forgetting, the amnesic syndrome, and the hippocampal arousal system. Psychological Review, 86, 44-60 Available at: Http://www.ncbi.nlm.nih.gov/ pubmed/451113 [Accessed January 15, 2018].

Wilson, M. A., \& McNaughton, B. L. (1994). Reactivation of hippocampal ensemble memories during sleep. Science, 265, 676-679 Available at: http://www.ncbi.nlm.nih.gov/pubmed/8036517 [Accessed January 12, 2018].

Wittenberg, G. M., Sullivan, M. R., \& Tsien, J. Z. (2002). Synaptic reentry reinforcement based network model for long-term memory consolidation. Hippocampus, 12, 637-647 Available at: http://www.ncbi.nlm.nih.gov/pubmed/12440578 [Accessed January 15, 2018].

Yang, G., Lai, C. S. W., Cichon, J., Ma, L., Li, W., \& Gan, W.-B. W.-B. (2014). Sleep promotes branch-specific formation of dendritic spines after learning. Science, 344, 1173-1178 Available at: http://www.ncbi.nlm.nih.gov/pubmed/24904169 [Accessed January 12, 2018].

Yoon, K., Buice, M. A., Barry, C., Hayman, R., Burgess, N., \& Fiete, I. R. (2013). Specific evidence of low-dimensional continuous attractor dynamics in grid cells. Nature Neuroscience, 16, 1077-1084 Available at: doi: 10.1038/nn.3450 [Accessed July 19, 2014].

Yordanova, J., Kolev, V., Wagner, U., Born, J., \& Verleger, R. (2012). Increased alpha $(8-12 \mathrm{~Hz})$ activity during slow wave sleep as a marker for the transition from implicit knowledge to explicit insight. Journal of Cognitive Neuroscience, 24, 119-132 Available at: http://www.ncbi.nlm.nih.gov/pubmed/21812555 [Accessed May 31, 2018].

Zhang, H., Watrous, A. J., Patel, A., \& Jacobs, J. (2018). Theta and alpha oscillations are traveling waves in the human neocortex. Neuron, 98, 1269-1281.e4 Available at: http://www.ncbi.nlm.nih.gov/pubmed/29887341 [Accessed August 21, 2018]. 